\title{
Inventory Dynamics and Business Cycles: What Has Changed? ${ }^{\dagger}$
}

\author{
Jonathan McCarthy ${ }^{\ddagger} \quad$ Egon Zakrajšek ${ }^{\S}$
}

June 2003

\begin{abstract}
Despite the recent patch of sluggish growth, the U.S. economy has experienced a period of remarkable stability since the mid-1980s. One popular explanation attributes the diminished variability of economic activity to information-technology led improvements in inventory management. Our results, however, indicate that the changes in inventory dynamics since the mid-1980s played a reinforcing - rather than a leading-role in the volatility reduction. Movements in the volatility of manufacturing output over the past three decades almost entirely reflect changes in the variability of the growth contribution of sales. Although the volatility of total inventory investment has fallen, the decline occurred well before the mid-1980s and was driven by the reduced variability of materials and supplies. Our analysis does show that since the mid-1980s inventory dynamics have played a role in stabilizing manufacturing production: Inventory "imbalances" tend to correct more rapidly, and the quicker response of inventories to monetary policy and commodity price shocks buffers production from fluctuations in sales to a greater extent. But more extensive production smoothing and faster dissolution of inventory imbalances appear to be a consequence of changes in the way industry-level sales and aggregate economic activity respond to shocks, rather than a cause of changes in macroeconomic behavior.
\end{abstract}

JEL Classification: E32, E22, D24

KEYWORDS: inventories, inventory management, business cycles, GDP volatility

\footnotetext{
${ }^{\dagger}$ We thank Doug Elmendorf, Michael Feroli, Mark Gertler, Kenneth Kuttner, Andrew Levin, Dan Sichel, Eric Swanson, Stacey Tevlin, Jonathan Wright, and participants of the New York Fed Domestic Research Brown Bag seminar and the Federal Reserve Board macro workshop for helpful comments. Amanda Cox provided outstanding research assistance. The views expressed in this paper are solely the responsibility of the authors and should not be interpreted as reflecting the views of the Board of Governors of the Federal Reserve System, the Federal Reserve Bank of New York, or of any other person associated with the Federal Reserve System.

${ }^{\ddagger}$ Research Department, Federal Reserve Bank of New York, 33 Liberty Street, New York, NY, 10045. Email: jonathan.mccarthy@ny.frb.org; Tel: (212) 720-5645.

${ }^{\S}$ Corresponding author: Division of Monetary Affairs, MS-84, Board of Governors of the Federal Reserve System, 20th Street \& Constitution Avenue, NW, Washington D.C., 20551. Email: egon.zakrajsek@frb.gov; Tel: (202) 728-5864.
} 


\section{Introduction}

The economic stability of the 1983-2000 period stands out in marked contrast to the frequent and relatively severe cyclical fluctuations that characterized the American economy through much of the twentieth century. Between 1983 and 2000, the U.S. experienced two of the longest economic expansions and one of the mildest and shortest recessions on record. While the economic downturn in 2001 and the subsequent wobbly recovery have shown that the business cycle is far from dead, the striking decrease in the volatility of real aggregate output since the mid-1980s continues to intrigue researchers. ${ }^{1}$

Economists have advanced a number of explanations for the decline in the volatility of aggregate output; see Stock and Watson (2002) for a comprehensive review. Among the leading hypotheses is that more transparent and credible monetary policy since the "Volcker deflation" of the early 1980s has resulted in a more stable economic environment. A second, "good luck," theory argues that economic shocks (e.g., productivity and commodity price shocks) have been milder over the past twenty years. A third hypothesis, which has received a great deal of attention, points to the widespread adoption of better business practicesin particular, inventory management techniques - spurred by technological advances of the past two decades. ${ }^{2}$

In this paper, we focus principally on the better business practices hypothesis, or what we call the inventory conjecture. Proponents of this view argue that while the concept of integrated physical distribution management has been around since the 1960s, advances in information technology over the past two decades have only just recently made its widespread implementation possible. ${ }^{3}$ As a result, firms are now better able to control production and delivery processes, and thus identify and resolve inventory imbalances more rapidly. Because enterprises now operate on the basis of essentially the same information set, economic decisions of firms within and across industries may have become more synchronized. In the aggregate, synchronous efforts to correct emerging inventory imbalances may induce

\footnotetext{
${ }^{1}$ McConnell and Perez-Quiros (2000) provided the first rigorous evidence of a decline in real GDP volatility, which their statistical techniques placed in the first quarter of 1984. Subsequently, a number of studies employing different statistical methods confirmed that real GDP has become more stable since the mid-1980s; see, for example, Kim, Nelson, and Piger (2001), Ahmed, Levin, and Wilson (2001), Sensier and van Dijk (2001), Blanchard and Simon (2001), and Stock and Watson (2002). Unlike McConnell and Perez-Quiros (2000), however, these studies found that the decline in GDP volatility is emblematic of reduced volatility in many economic series, both real and nominal, over the past two decades.

${ }^{2}$ Other possible factors such as changes in data construction, a shift in the composition of output from goods toward services, and changes in fiscal policy appear to have played relatively unimportant roles in the step-down of volatility since the mid-1980s.

${ }^{3}$ Integrated physical distribution management is a total system approach to the management of interrelated activities such as transportation, warehousing, order processing, inventory/production scheduling, and consumer service. According to a survey of firms in the late 1970s by Lambert and Mentzer (1978), the lack of necessary cost data - in particular, inventory carrying costs at different stages of production-had seriously hampered a full, successful implementation of this system.
} 
a steeper initial contraction in economic activity, but because these imbalances are more readily contained, they are less persistent and inventory runoffs - and consequently business cycles - thus should be less severe.

Efforts by economists to attribute the reduction in the volatility of aggregate economic activity to improvements in inventory management - or to any other source for that purpose - are and will remain controversial. This is so because the step-down in volatility since the mid-1980s constitutes essentially a single episode in the evolution of the U.S. economy. Consequently, it is difficult to disentangle causal explanations from ones that are correlated with the reduction in volatility merely because of a coincidence of timing. The inventory conjecture is especially susceptible to this criticism, as it abounds with anecdotal evidence and case studies linking the information revolution with the use of this technology by firms to manage more efficiently their production and inventories.

Formal statistical evidence on the issue is also largely indirect. McConnell and PerezQuiros (2000) (MPQ hereafter), for example, trace the GDP volatility reduction to a narrow source - a structural break in the volatility of durable goods output. Because they do not find a similar decline in the variability of final sales of durable goods, MPQ argue that a more stable economy since the mid-1980s stems from a reduction in the volatility of inventory investment in that sector. Moreover, they argue, the timing of the break in the volatility of durable goods output occurs after the widespread adoption of just-in-time (JIT) techniques and computerized production and supply-chain management by U.S. manufacturers during the late 1970s and early 1980s. ${ }^{4}$ The effects of these innovations are evident in the decline in the aggregate inventory-sales ratio, as firms are able to meet production and sales with leaner stocks, and in a significant reduction in the time between ordering and receiving parts and other production materials (see McConnell, Mosser, and Perez-Quiros (1999)).

Earlier attempts to assess more directly the effects of changes in inventory control methods on the business cycle by Morgan (1991), Bechter and Stanley (1992), Little (1992), Allen (1995), and Filardo (1995) have reached mixed conclusions. These authors agree that the adoption of new inventory management techniques has resulted in a lower ratio of inventories to sales, but the impact of these innovations on cyclical fluctuations, at least through the mid-1990s, is ambiguous.

More recently, Kahn, McConnell, and Perez-Quiros (2001) developed a theoretical model incorporating both inventories and information technology. In their model, advances in

\footnotetext{
${ }^{4}$ Pioneered by the Japanese, JIT management of production allows firms to keep a minimum of inventories of work-in-progress, raw materials, parts, and other supplies, thereby lowering inventory financing costs. Because JIT delivery methods respond mostly to the current conditions on the factory's floor, they work best when demand is predictable. JIT practices, however, can be combined with the computer-driven systems that initiate production and place orders in anticipation of future demand. Because businesses have to purchase the necessary computer systems and train workers to use them, this technology is expensive relative to JIT; see Little (1992) for additional details.
} 
information technology improve information about final demand and thus lead to a lower ratio of inventories to sales and diminished output variability. Their simulation results, however, suggest that the quantitative effects of better information on the variability of inventory investment and, consequently, output are modest.

Following a different tack, Feroli (2002) calibrates a variant of the neoclassical growth model in which inventories enter the production function along with labor, nonresidential structures, and equipment and software $(\mathrm{E} \& \mathrm{~S})$. The key finding is that the sustained fall of E\&S prices relative to the price of inventories has caused firms to substitute E\&S for inventory stocks, thus inducing a decline in the aggregate inventory-sales ratio. ${ }^{5}$ The technical substitution of capital equipment for inventory stocks, however, has a negligible effect on the volatility of output.

In a recent study, Irvine and Schuh (2003), using an accounting framework and industrylevel data, attribute about one-half of the decline in gross output volatility since the mid1980s to lessened variability of inventory investment in both the manufacturing and trade sectors; the remaining one-half can be accounted for by the diminished comovement of sales between industries. Although they do not directly examine the inventory adjustment process nor the interaction between aggregate shocks and industry-level inventory dynamics, they interpret their results as reflecting a growing sophistication of supply and distribution chains among firms and across industries.

With the issue far from resolved and intriguing evidence abounding, we investigate the inventory conjecture utilizing disaggregated (by industry and stage of fabrication), highfrequency data. Our empirical strategy consists of two parts. To determine more accurately the changes in the volatility of manufacturing activity, as well as to compare the timing of these changes with the decline in the variability of aggregate output, we first examine the evolution of the volatility of production, shipments, and inventories at the broad sectoral level. In the second part, we assess whether changes in industry-level inventory adjustment since the mid-1980s have stabilized production to a greater extent than previously, as suggested by the inventory conjecture.

Our decomposition of the unconditional variance of the growth rate of manufacturing output indicates that the observed decline in production volatility in that sector since the mid-1980s stems overwhelmingly from a reduction in the volatility of shipments rather than the volatility of finished goods inventory investment. Next, we parse the variance of total inventory investment and find that it has been trending lower since the mid-1970s, driven largely by a substantial decrease in the volatility of its materials and supplies component. The timing of the decline in the variance of inventory investment in materials and supplies is

\footnotetext{
${ }^{5}$ As noted by Feroli (2002), this explanation is consistent with the inventory conjecture, which holds that the reduction in average inventory holdings over the past two decades is a direct result of firms utilizing cheaper information processing equipment and software.
} 
consistent with the adoption of JIT and other inventory management innovations in response to the oil price shocks of the 1970s. However, there appears to be little systematic reduction in the unconditional variance of inventory investment at other stages of fabrication.

In the second part of the paper, we employ two empirical models to study the changes in inventory adjustment since the mid-1980s. The first model, a vector autoregression, links industry shipments, relative prices, and inventories at different stages of production to a model typically used to identify the effects of monetary policy and other shocks on aggregate economic activity. In addition, we estimate industry-level inventory adjustment speeds at different stages of fabrication, using a version of the accelerator model with timevarying targets. We find that industry-level responses of inventories to monetary policy and supply shocks since the mid-1980s are consistent with firms buffering production from sales fluctuations to a greater extent than in the earlier period. Our estimates of adjustment speeds also indicate a significantly faster dissipation of inventory imbalances since the mid1980s, especially for finished goods and work-in-progress stocks.

The prevalence of production smoothing and faster inventory adjustment in the later period, however, appears to be driven largely by changes in the way aggregate economic activity and industry shipments respond to aggregate shocks. We thus interpret our results as suggesting that changes in the macroeconomic environment-most likely a shift to a more transparent and less activist monetary policy - were likely the key factors in the moderation of output volatility. Improvements in inventory control methods, however, appear to have amplified the reduction in output volatility.

\section{Data}

Throughout our analysis, we use monthly, industry-level (2-digit SIC) data for the manufacturing sector provided by the Bureau of Economic Analysis (BEA). ${ }^{6}$ Our key variables for the twenty manufacturing industries - sales, materials and supplies inventories, work-inprogress inventories, and finished goods inventories - are seasonally adjusted and reported in millions of chain-weighted 1996 dollars. Inventory stocks are measured as of the end-ofperiod, and sales are defined as the value of shipments. The sample covers the period from January 1967 through December 2000, yielding a balanced panel of 408 monthly observations per industry, for a total of 8,160 industry/month observations.

Although the manufacturing sector accounts for a relatively small (and declining) share

\footnotetext{
${ }^{6}$ In spring 2001, the BEA and the Census Bureau, the BEA's source of the raw book-value of inventories used to calculate real inventory stocks, replaced the SIC system with the North American Industrial Classification System (NAICS). At the time of this paper, NAICS-classified data were available only starting in the early 1990s. For this reason, as well as to make the paper comparable to earlier studies, we use industry-level data aggregated according to the SIC system. The twenty manufacturing industries, along with their respective 2-digit SIC codes, are listed in the Appendix.
} 
of aggregate economic output (26.5 percent of GDP in 1967 and 15.9 percent in 2000), its share of goods production is more substantial. Manufacturing firms accounted for more than 80 percent of durable goods GDP in the late 1960s, and even though this share has fallen over the years, they still accounted for more than 50 percent of durable goods GDP in 2000. In the nondurable goods sector, by contrast, the manufacturing share of GDP has remained fairly steady at about 35 percent over this period.

At the beginning of our sample period, U.S. manufacturers also held more than 50 percent of aggregate inventory stocks, but this share has fallen to about 35 percent in 2000. By sector, the manufacturing share of durable goods inventories has declined from 60 percent in the late 1960s to about 40 percent by the end of 2000; for nondurable goods, the manufacturing share has decreased from 40 percent to about 25 percent over the same period. Despite the diminished role of manufacturing firms in overall economic activity, their still-sizable presence in goods production, along with the fact that the factory sector was an early adopter of inventory and production control innovations, warrants our narrow focus.

\section{Evolution of Volatility}

In this section, we establish some facts about the variability of manufacturing production, sales, and inventories at the sectoral level. This provides a more direct comparison to the previous research documenting the decline in the volatility of similar, though typically broader, components of GDP. We begin by parsing out changes in the variance of sectoral output to changes in the variance of sales and inventory investment as well as to changes in their covariance. We then turn to the evolution of volatility of total inventory investment and of inventory investment at each stage of fabrication.

\subsection{Methodology}

Because our data are chain-weighted, the components of an aggregate are not additive (see Whelan (2000)). The growth contributions of components, however, do add up to the growth rate of the chain-weighted aggregate. In addition, because the growth contribution of a component is approximately equal to its share of the nominal aggregate times the component's growth rate, working with growth contributions adjusts for the fact that a very volatile component may have little effect on the overall volatility if it accounts for a small share of the aggregate. Accordingly, we decompose the growth rate of output and total inventories into the growth contributions of their respective components. In particular, 
we write the growth rate of a generic aggregate $X_{t}$ in period $t$, denoted by $\% \Delta X_{t}$, as

$$
\% \Delta X_{t}=\sum_{j} g_{t}^{j}
$$

where $g_{t}^{j}$ is the growth contribution of component $j$ in period $t$.

As in Blanchard and Simon (2001), our measure of the time-varying volatility of the growth contribution $g_{t}^{j}$ is a rolling unconditional sample standard deviation. We use a three-year (36-month) window to compute these standard deviations, with rates of change expressed at a monthly basis. Because the monthly disaggregated data are volatile, we employ a robust estimator of scale proposed by Rousseeuw and Croux (1993a) to mitigate the effect of outliers. ${ }^{7}$ The comovements between growth contributions over time are measured by rolling correlations, again computed over a 36-month window. To minimize the effect of outliers, we report 5-percent trimmed correlations, computed using the standardized sums and differences method (see Huber (1981)).

\subsection{Volatility of Output}

Our starting point is the standard NIPA accounting identity

$$
Q_{i t} \equiv S_{i t}+\Delta H_{i t}
$$

where $Q_{i t}$ denotes real (gross) output or production of sector (industry) $i$ in period $t, S_{i t}$ are real sales, and $H_{i t}$ are real finished goods inventory stocks at the end of period $t{ }^{8}$ Using (3.2.1), we decompose the growth rate of output into the growth contribution of sales $g_{i t}^{S}$ and the growth contribution of finished goods inventory investment $g_{i t}^{\Delta H}$ :

$$
\% \Delta Q_{i t}=g_{i t}^{S}+g_{i t}^{\Delta H} .
$$

\footnotetext{
${ }^{7}$ In particular, we use the $Q_{n}$ estimator with a small-sample correction factor derived in Rousseeuw and Croux (1993b). This estimator has a 50 percent breakdown point, is suitable for asymmetric distributions, and attains very high efficiency for Gaussian distributions. In addition, we examined the evolution of volatility of our key series using a GARCH model. The contours in the conditional variance of output, sales, and inventory investment from a GARCH specification match up closely with those of the unconditional volatility reported in the paper.

${ }^{8}$ Although we define output using identity (3.2.1), we construct real output by calculating a proper chainaggregated output index; see Whelan (2000) for details. An additional issue concerning construction of an output measure is whether to include work-in-progress inventories in the inventory investment term $\Delta H_{i t}$. According to Blinder (1986), including work-in-progress inventories may provide a more accurate economic measure of output, though restricting inventory investment to finished goods is more standard in empirical work on inventory dynamics. We performed our analysis using both measures of output, and our results were virtually identical, as the correlation between the growth rates of the output measures is 0.94 for the durable goods and 0.98 for the nondurable goods sector.
} 
The growth contributions are calculated in a manner consistent with chain aggregation used in the NIPA and thus are well-defined for both positive and negative values of $\Delta H_{i t}$.

The variance of the growth rate of real output for sector $i$ is then given by

$$
\operatorname{Var}\left(\% \Delta Q_{i t}\right)=\operatorname{Var}\left(g_{i t}^{S}\right)+\operatorname{Var}\left(g_{i t}^{\Delta H}\right)+2 \times \operatorname{Cov}\left(g_{i t}^{S}, g_{i t}^{\Delta H}\right)
$$

The paths of the standard deviations corresponding to the variance terms in (3.2.2) are presented in Figure 1. To provide a reference for possible volatility breaks, thin vertical lines labeled 1984:Q1 and 1986:Q3 mark the break dates in the volatility of durable and nondurable goods GDP, respectively, as estimated by Kim, Nelson, and Piger (2001) (KNP hereafter). ${ }^{9}$ Shaded vertical bars denote NBER-dated recessions.

Surprisingly, neither sector of U.S. manufacturing appears to have experienced a marked decline in output growth volatility (the solid line) around their respective KNP break dates. In the durable goods sector (upper panel), output volatility is somewhat lower after the break date, though it does not decline decisively until the mid-1990s. In the nondurable goods sector (lower panel), output volatility begins to trend lower in the early 1980s, eventually touching a historically low level during the late 1990 s. $^{10}$

Another notable feature in Figure 1 is that the evolution of the volatility of the growth contribution of sales (dotted line) is strikingly similar to that of output volatility. ${ }^{11}$ The variability of the growth contribution of finished goods inventory investment (dashed line), by contrast, has remained in a narrow range throughout our sample period, and its movements are not well correlated with the swings in the volatility of output growth. Both of these observations do not offer much support to the idea that widespread changes in production and inventory management in the mid-1980s resulted in more stable economic environment.

According to (3.2.2), however, inventory investment could have still contributed to a lower output growth variance through changes in the sign or magnitude of the covariance between the growth contributions of inventory investment and sales. However, in the durable goods sector, the movement in the correlation between the growth contributions of inventory investment and sales shows no clear pattern, and its magnitude is generally modest (Figure 2, upper panel). In the nondurable goods sector (lower panel), by contrast, this correlation has declined steadily during the past two decades, falling to about -0.6 by

\footnotetext{
${ }^{9}$ Ahmed, Levin, and Wilson (2001) and Stock and Watson (2002) find similar dates using different methods.

${ }^{10}$ We also performed this analysis using the Federal Reserve Board's index of industrial production as an alternative measure of manufacturing output. In both sectors, the trends in output volatility using the industrial production index are quite similar to those shown in Figure 1.

${ }^{11}$ This finding is consistent with the results reported by Ramey and Vine (2001), who show that sales shocks in the U.S. automobile industry during the 1990s have been far more transitory than during the 1970s.
} 
the end of the 1990s. ${ }^{12}$ Although this would suggest that production smoothing may have become more prevalent in the nondurable goods sector, the driving force of the reduction in the volatility of production, according to Figure 1, was still the decline in the variability of sales. Overall then, Figures 1-2 suggest that even though the volatility of GDP declined markedly after the mid-1980s, there is little evidence that the timing coincides with the stabilization of manufacturing production and inventory investment.

\subsection{Volatility of Inventories}

According to the NIPA, it is total inventory investment rather than finished goods inventory investment that enters into the measurement of GDP. In manufacturing, total inventories $\left(I_{i t}\right)$ consist of inventories of materials and supplies $\left(M_{i t}\right)$, work-in-progress $\left(W_{i t}\right)$, and finished goods $\left(H_{i t}\right)$. It is quite plausible that improved management of inventories at earlier stages of fabrication is responsible for the diminished volatility of aggregate output. Using (3.1.1), the growth of total inventories, $\% \Delta I_{i t}$, can then be written as

$$
\% \Delta I_{i t}=g_{i t}^{M}+g_{i t}^{W}+g_{i t}^{H},
$$

where $g_{i t}^{M}$ is the growth contribution of materials and supplies, $g_{i t}^{W}$ is the growth contribution of work-in-progress inventories, and $g_{i t}^{H}$ is the growth contribution of finished goods inventories. We can then parse the variance of $\% \Delta I_{i t}$ into the variances of its growth contributions and the covariances between growth contributions at different stages of fabrication.

The results of this exercise are summarized in Figures 3-5. The top panel of Figure 3a shows the evolution of the standard deviation of the growth rate of total inventories in the durable goods sector, while the bottom panel depicts the paths of the volatilities of growth contributions by stage of production. The same information for the nondurable goods sector is presented in Figure 3b. To gauge the relative importance of inventories at different stages of fabrication, we plot a rolling 36-month average share of each type of inventory in Figure 4. Comovements between growth contributions in (3.3.1) are shown in Figure 5.

As seen in the top panels of Figures $3 \mathrm{a}$ and $3 \mathrm{~b}$, the volatility of the growth rate of total inventories in both the durable and nondurable goods sectors spiked in the aftermath of the first oil shock in 1973, the economic turmoil of the 1980-83 period, and the 1990-91 recession. These jumps in volatility are not surprising, given the well-documented role of inventory investment during cyclical retrenchments; see, for example, Ramey and West (1999). Most striking in both panels, however, is the inverted V-pattern of the standard deviation of total

\footnotetext{
${ }^{12}$ Blanchard and Simon (2001) report a similar change in the covariance between inventories and sales using data for the broader nonfarm business sector. Irvine and Schuh (2003) also find widespread evidence of the change in the comovement between sales and inventory investment after the mid-1980s among manufacturing and trade industries.
} 
inventory investment straddling KNP's estimated dates of volatility reduction, a pattern that obscures the reduction in inventory investment volatility that began in the late 1970s.

The decrease in the standard deviation of total inventory growth during the late 1970s coincides with a decline in the volatility of the growth contribution of materials and supplies (Figures $3 \mathrm{a}$ and $3 \mathrm{~b}$, bottom panels). The reduction in the volatility of materials and supplies (dashed line) had begun in the mid-1970s, around the time when U.S. manufacturers started to adopt JIT methods to reduce lead times and to better manage supply channels in the wake of the first oil crisis. At the same time, there were modest declines in the volatility of the growth contribution of finished goods inventories. The volatility of the growth contribution of work-in-progress inventories, by contrast, displayed no discernible trend.

These patterns suggest that firms' efforts during the late 1970s to stabilize inventory fluctuations were largely concentrated on their holdings of materials and supplies. Still, because we are working with growth contributions, it is possible that changes in the composition of inventories have masked a decline in the volatility of other inventory components. As shown in Figure 4, however, the shares of inventories at different stages of fabrication have remained fairly constant over most of our sample period. The largest compositional shift occurred in the early 1990s among durable good producers (top panel), who over the course of the decade significantly reduced the portion of inventories held as work-in-progress. ${ }^{13}$

The last set of factors that could account for the movements in the volatility of total inventory investment are the correlations between the growth contributions of inventories at different stages of fabrication (Figure 5). Most notably, these correlations moved largely in tandem in the durable goods sector during most of the 1980s (top panel), which contributed to the inverted V-pattern of inventory investment volatility discussed earlier. In addition, the negative comovement of these factors in the late 1990s counteracted a runup in the standard deviation of the growth contribution of finished goods inventories (see Figure 3a, bottom panel). In the nondurable goods sector, by contrast, correlations between the growth contributions of inventories at different stages of fabrication show no systematic pattern throughout the sample period (Figure 5, bottom panel).

In sum, the volatility patterns of production and inventory investment in manufacturing do not change dramatically in the mid-1980s as suggested by the inventory conjecture. Rather, the volatility of output in the nondurable goods sector started to trend lower as early as the mid-1970s, whereas in the durable goods sector, the most significant reduction in output volatility occurred during the early 1990s. More importantly, the reduction in output volatility in the factory sector is closely associated with a decrease in the variability of sales. Although total inventory investment has become less volatile, the decline in the standard

\footnotetext{
${ }^{13}$ Although the exact timing differs across durable goods industries, the fraction of inventories designated as work-in-progress generally declined after the 1990-91 recession. The reductions are especially notable in the large industries, SICs 35-38.
} 
deviation of the growth rate of total inventories was driven primarily by a steady reduction in the volatility of its materials and supplies component that started in the aftermath of oil price shocks of the 1970s.

\section{Inventory Adjustment}

So far, we have examined the volatility of manufacturing production and inventory investment in isolation from the rest of the economy. However, manufacturing inventory behavior may have changed in a manner consistent with the inventory conjecture, but the change in inventory dynamics as part of a business cycle propagation mechanism may have been a result of developments in the rest of the economy. We therefore next examine changes in the inventory adjustment process, while controlling for changes in the macroeconomic environment.

Our approach is twofold. First, we use a vector autoregression (VAR) model to examine changes in the adjustment of inventories following aggregate shocks. The multivariate framework allows us to identify some linkages implicit in the inventory conjecture and to track how responses of inventories at the industry level to common shocks may have changed. Second, we estimate industry-specific error-correction models for inventory investment at each stage of fabrication. This approach provides a more direct method to assess changes in the inventory adjustment process, because the error-correction parameter measures the speed with which inventories move toward their target level.

\subsection{Inventory Adjustment and Aggregate Shocks}

We begin by examining changes in the industry-level impulse response functions following monetary policy and aggregate supply shocks. The key feature of our specification and identification scheme is that the VAR equations can be separated into two exogenous blocks -industry and aggregate. ${ }^{14}$ The industry block interlinks the dynamics of industry sales, relative output price, and inventories given the behavior of the aggregate variables. The aggregate block is a version of the Bernanke and Gertler (1995) model used to identify the effects of monetary policy and other shocks on aggregate economic activity.

In assuming block-exogeneity, we impose the restriction that the industry-level variables do not enter into the aggregate block, whereas the aggregate variables enter into the industry

\footnotetext{
${ }^{14}$ Barth and Ramey (2001) use a similar block-exogenous VAR in their study of the "cost channel" of monetary transmission mechanism.
} 
block. In particular, the reduced form of the VAR for industry $i$ is given by

$$
\left[\begin{array}{c}
\mathbf{x}_{i t} \\
\mathbf{y}_{t}
\end{array}\right]=\mathbf{A}_{i}(L)\left[\begin{array}{c}
\mathbf{x}_{i t-1} \\
\mathbf{y}_{t-1}
\end{array}\right]+\left[\begin{array}{l}
\mathbf{e}_{i t} \\
\mathbf{u}_{t}
\end{array}\right] ; \quad i=1,2, \ldots, N
$$

where $\mathbf{x}_{i t}=\left(s_{i t} \bar{p}_{i t} m_{i t} h_{i t}\right)^{\top}$ is a vector of industry-specific variables consisting of (in logarithms) sales $s_{i t}$, relative output price $\bar{p}_{i t}$, materials and supplies inventories $m_{i t}$, and the sum of work-in-progress and finished goods inventories $h_{i t}$. The output price in industry $i$ is measured relative to the PCE price deflator, our aggregate price measure.

The aggregate block is described by the vector $\mathbf{y}_{t}=\left(e_{t} p_{t} p_{t}^{c} r_{t}\right)^{\top}$ comprising the logarithm of a measure of aggregate economic activity $e_{t}$, the logarithm of the aggregate price level $p_{t}$, the logarithm of a commodity price index $p_{t}^{c}$, and the effective Federal funds interest rate $r_{t}$. Because we use monthly data, GDP is not readily available as a measure of aggregate economic activity. As an alternative, we use private nonfarm payroll employment. ${ }^{15}$ The commodity price index is the Journal of Commerce-Economic Cycle Research Institute Industrial Price Index.

Given our block-exogeneity assumption, the $(8 \times 8)$ industry-specific matrix polynomial in the lag operator $L$ in (4.1.1) takes the following form:

$$
\mathbf{A}_{i}(L)=\left[\begin{array}{cc}
\mathbf{A}_{i, 11}(L) & \mathbf{A}_{i, 12}(L) \\
\mathbf{0} & \mathbf{A}_{22}(L)
\end{array}\right]
$$

The $(4 \times 4)$ submatrix of zeros in the lower left corner encompasses the assumption that lagged values of the industry variables do not affect the dynamics of the aggregate variables.

To identify the structural shocks underlying the reduced-form VAR innovations, we place restrictions on the contemporaneous relationships between the variables. The first set of restrictions comes from the block exogeneity assumption-industry variables have no contemporaneous effect on the aggregate variables. The second is that the aggregate structural shocks are identified, as in Bernanke and Gertler (1995), by a recursive ordering of private employment, price level, commodity prices, and the Fed funds rate. The third is that aggregate variables affect some industry variables contemporaneously, which allows for a degree of strategic complementarity. ${ }^{16}$ In particular, the level of aggregate employment may affect industry output and price; the aggregate price level may influence industry-

\footnotetext{
${ }^{15}$ According to Warnock and Warnock (2000), volatility in aggregate employment has also fallen since the mid-1980s. To explore the robustness of our results to the choice of the aggregate activity variable, we also performed the VAR analysis using the index of industrial production and real personal consumption expenditures in place of private employment. The substantive conclusions were the same as those presented in the text.

${ }^{16}$ See Cooper and John (1988) and Blanchard and Kiyotaki (1987) for macro models containing such complementarities.
} 
level prices; and commodity prices may affect the inventory of materials and supplies. The fourth assumption is that industry sales and relative prices may affect inventories contemporaneously, but not vice versa. This assumption reflects the stickiness of price and production plans that underlie many New Keynesian models and seems reasonable given the monthly frequency of our data. The last assumption is that inventories at each stage of fabrication are determined contemporaneously.

Under these restrictions, the relationship between the VAR innovations and structural shocks can be written as:

$$
\mathbf{A}_{i 0}\left[\begin{array}{l}
\mathbf{e}_{i t} \\
\mathbf{u}_{t}
\end{array}\right]=\left[\begin{array}{l}
\boldsymbol{\epsilon}_{i t} \\
\boldsymbol{\nu}_{t}
\end{array}\right] ; \quad\left[\begin{array}{l}
\boldsymbol{\epsilon}_{i t} \\
\boldsymbol{\nu}_{t}
\end{array}\right] \sim \operatorname{MVN}\left(\mathbf{0}, \boldsymbol{\Sigma}_{i}\right), \quad i=1,2, \ldots, N,
$$

where $\boldsymbol{\Sigma}_{i}$ is a diagonal covariance matrix of structural shocks, and

$$
\mathbf{A}_{i 0}=\left[\begin{array}{cccccccc}
1 & 0 & 0 & 0 & a_{i, 15} & 0 & 0 & 0 \\
a_{i, 21} & 1 & 0 & 0 & a_{i, 25} & a_{i, 26} & 0 & 0 \\
a_{i, 31} & a_{i, 32} & 1 & a_{i, 34} & 0 & 0 & a_{i, 37} & 0 \\
a_{i, 41} & a_{i, 42} & a_{i, 43} & 1 & a_{i, 45} & 0 & 0 & 0 \\
0 & 0 & 0 & 0 & 1 & 0 & 0 & 0 \\
0 & 0 & 0 & 0 & a_{65} & 1 & 0 & 0 \\
0 & 0 & 0 & 0 & a_{75} & a_{76} & 1 & 0 \\
0 & 0 & 0 & 0 & a_{85} & a_{86} & a_{87} & 1
\end{array}\right] .
$$

One issue in estimating the VAR is whether or not to remove trends from the series. Changes in the inventory-sales ratios owing to the adoption of new management techniques have certainly altered the relationship between inventories and sales at low frequencies, which may obscure changes in inventory dynamics at business cycle or higher frequencies. Accordingly, we used a one-sided exponential smoother with a gain parameter of 0.25 to remove a stochastic trend from each of our series; see, for example, Gourieroux and Monfort (1997). An attractive feature of this detrending procedure is that it preserves high-frequency temporal patterns that may be distorted by two-sided filters such as the Hodrick-Prescott and Baxter-King band-pass filters. ${ }^{17}$ Given the high dimensionality of our system, another issue is parameter parsimony. To conserve degrees of freedom, we impose an asymmetric lag structure on our model — seven lags on the variables in the aggregate block and four lags on the variables in the industry block. ${ }^{18}$

\footnotetext{
${ }^{17}$ As a robustness check, we tried several other values for the gain parameter in the typical range between 0.15 and 0.30 , with negligible effects on our result. We also estimated the VAR in log levels. At shorter horizons, the focus of our analysis, the pattern of impulse responses for employment, sales, and inventories was substantively similar to those we present in the paper.

${ }^{18}$ As suggested by Kilian (2001) and Ivanov and Kilian (2001), we determined the lag structure using the
} 
The block-exogeneity assumption implies that the reduced-form specification (4.1.1) can be estimated industry by industry. ${ }^{19}$ Although the model is not recursive, standard likelihood techniques can then be used to estimate the structural parameters in $\mathbf{A}_{i, 0}$ and $\boldsymbol{\Sigma}_{i}$ for each industry (see Hamilton (1994), p. 330-33). Because of the volatility of the Fed funds rate associated with the Volcker monetarist experiment, we exclude the 1979-83 period from the estimation. In addition, omitting the period associated with exceptional volatility and restructuring in the manufacturing sector should enhance our ability to detect differences in inventory dynamics across the subsamples. We thus estimate the structural parameters over two periods-1967:I-1978:XII and 1984:I-2000:XII — and compute the orthogonalized impulse responses. Using the industry-specific average shares of sales and inventories within each sample period, we then aggregate industry responses to the sectoral level.

\subsubsection{Responses to Monetary Policy Shocks}

In this section, we examine the responses to a 50-basis-point shock in the Fed funds rate equation, commonly identified as a contractionary monetary policy shock. Figure 6a depicts impulse responses for the aggregate block. Figures $6 \mathrm{~b}$ and $6 \mathrm{c}$ contain impulse responses for the durable and nondurable goods sectors, respectively; in addition to the impulse responses of the four variables in the industry block, the two figures also depict the response of the log inventory-sales ratio for both materials and supplies and finished goods stocks, constructed as the difference between the responses of the log-level of inventories and the log-level of sales.

Aggregate block: According to Figure 6a, the behavior of the employment in the early period (1967:I-1978:XII) displays the familiar response of aggregate economic activity to an unanticipated monetary policy tightening, as discussed, for example, by Bernanke and Gertler (1995). Employment, relative to trend, does not begin to decline until about six months after the policy tightening, but the response is persistent thereafter, with private employment running below trend up to 36 months after the initial shock. The response of employment in the later period (1984:I-2000:XII), by contrast, is quite different. Employment falls below trend much more quickly, with the trough occurring six to nine months after the unanticipated monetary policy tightening. Moreover, the response is considerably less persistent, dying out within two years after the shock. These differences in the employment responses will have a substantial effect on the dynamics of industry-level sales and

Akaike Information Criterion, allowing for some additional lags to preclude underfitting. We examined a number of symmetric and asymmetric lag structures, and the substantive conclusions are very similar to those presented in the paper.

${ }^{19}$ SIC 21 (Tobacco \& Related Products) is omitted from the analysis because of suspect data. 
inventories, even though the response of the Fed funds rate, at shorter horizons, is quite similar across the two periods.

Industry block: In the durable goods sector, there is a noticeable difference in the responses of sales between the two periods (Figure 6b). The response of sales in the earlier period, like that of aggregate employment, is one typically expected after a contractionary monetary policy shock: After a delayed decline, sales are persistently below trend for more than two years. The response of sales in the post-1983 period, again much like that of the aggregate activity, is quicker, larger, but less persistent. Sales bottom out about six months after the shock - roughly at the same time as the trough of the employment responseand are back to baseline within about one year after the shock. In both sample periods, the initial increase in sales is consistent with the behavior of relative prices, which decline immediately after the policy tightening.

The differences in the responses of aggregate employment and sectoral sales between the two periods are associated with significant differences in the dynamics of inventories. Compared with the later period, the response of inventories at both stages is significantly smaller in the pre-1979 period, despite the sizable response of sales to a monetary policy tightening. This pattern suggests a minor role for finished goods inventories as a buffer against fluctuations in demand, implying larger swings in production in the pre-1979 period. ${ }^{20}$ In the later period, by contrast, the response of inventories at both stages of fabrication is large and positive at shorter horizons. Given the response of sales, the response of finished goods inventories is consistent with production smoothing, which would attenuate the volatility of output growth in the aftermath of an unexpected policy tightening.

The differences in the responses of inventories conditional on sales are clearly seen in the dynamics of the inventory-sales ratios. In the pre-1979 period, the responses of the ratios are primarily driven by the dynamics of sales, as inventories react little to a monetary policy shock. In the post-1983 period, however, the responses of the ratios largely reflect the accumulation of inventories in the face of slowing demand, a pattern that helps to stabilize production and results in less volatile output growth.

Compared with the durable goods sector, the magnitude of responses in the nondurable goods sector, with the exception of relative prices, is smaller (Figure 6c). Still, the pattern of sales responses is similar to that in the durable goods sector: A persistent, below-trend response in the pre-1979 period, and a less persistent decline in the post-1983 period. The response of materials and supplies is relatively muted in both periods, although materials and supplies inventories track sales much more closely during the post-1983 period than in

\footnotetext{
${ }^{20}$ This finding is consistent with the empirical literature on inventories, which generally has found that output is more variable than sales; see, for example, Ramey and West (1999).
} 
the pre-1979 period. ${ }^{21}$ For finished goods inventories, the differences in responses between the two periods are similar to those in the durable goods sector. The response in the earlier period is very small, while the response in the later period is immediate, positive, and large, a pattern that is consistent with production smoothing given the dynamics of sales in this period.

In general, the dynamics of inventories in both sectors following a contractionary monetary policy shock suggest that inventories in the post-1983 period have been used with greater success to shield production from a decline in sales. This behavior is evident across stages of fabrication in the durable goods sector, a segment of the U.S. economy that, by many measures, experienced the greatest reduction in the volatility of output since the mid-1980s. However, much of the change in the behavior of inventories between the two periods reflects changes in the response of industry-level sales and aggregate employment to an unanticipated monetary policy tightening. Both display a swifter, though considerably less persistent, reaction to monetary policy shocks, resulting in a smoother and shorter-lived inventory adjustment.

\subsubsection{Responses to Commodity Price Shocks}

We now examine the responses to a commodity price shock, which can be thought of as a negative supply shock. In the aggregate block, a positive commodity price shock exerts upward pressure on the aggregate price level, inducing a rise in the Fed funds rate to stave off inflation. In the industry block, this shock has a direct effect on the holdings of materials and supplies. The responses to this shock, standardized to 1 percent in each period, are presented in Figures $7 \mathrm{a}-7 \mathrm{c}$.

Aggregate block: In the earlier period, employment responds sluggishly to the negative supply shock; it rises for the first six months, then falls over the rest of the year. A persistent trough lasting almost a year follows the decline. The negative gap then gradually dissipates, and employment returns to trend after about three years. In the later period, by contrast, the employment swings are much smaller as well as less persistent; indeed, employment returns to trend within two years after the shock. As expected, the aggregate price level increases in both periods following a negative supply shock, but the response in the later period is noticeably smaller and less persistent. One reason for the more muted response of prices in the later period is that monetary policy policy appears to have become more aggressive in counteracting inflationary pressures associated with commodity price shocks-

\footnotetext{
${ }^{21}$ Indeed, over the horizon shown, the correlation between the response of sales and the response of materials and supplies inventories is 0.33 in the post-1983 period, compared with -0.01 in the earlier period, a pattern consistent with the adoption of JIT management practices, which reacts more promptly to current economic conditions.
} 
the immediate response of the funds rate in the post-1983 period is almost twice as large as that of the earlier period.

Industry block: The differences between the two periods in the aggregate responses are reflected in the responses of sectoral sales and inventories (Figures $7 \mathrm{~b}$ and $7 \mathrm{c}$ ). Overall, the responses of durable and nondurable goods sales in the earlier period display larger and more persistent oscillations than the responses in the later period. In addition, sales in both sectors bottom out earlier and return to trend quicker in the post-1983 period, a pattern similar to that of the aggregate employment.

The differences in the responses of sales between the two periods lead to notable differences in the behavior of inventories, especially in the durable goods sector (Figure $7 \mathrm{~b}$ ). In the pre-1979 period, both the materials and supplies and finished goods inventories in the durable goods sector are liquidated in the immediate aftermath of the shock. At the same time sales rise, exacerbating the decline in the inventory-sales ratios at shorter horizons. When sales start to weaken after about six months, both ratios begin to increase, and the resulting inventory overhangs persist for nearly two years. The joint dynamics of sales and inventories are consistent with production smoothing, but because finished goods inventory movements relative to those of sales are small, the resulting production fluctuations are nearly as large as those of sales.

In the post-1983 period, by contrast, stocks of materials and supplies and finished goods accumulate rapidly following the shock. In the durable goods sector, the inventory buildup peak coincides with the trough in sales. As sales return to trend, inventory stocks are gradually depleted, and the inventory-sales ratio at each stage of fabrication declines. Inventory movements in the post-1983 period are considerably smoother than those in the earlier period, and inventories at all stages of fabrication are better able to absorb fluctuations in demand, resulting in a less variable output growth when compared with that of the pre-1979 period.

In general, we observe similar inventory dynamics in the nondurable goods sector (Figure $7 \mathrm{c}$ ). One notable exception is the behavior of materials and supplies. In the pre-1979 period, stocks of materials and supplies exhibit large and persistent oscillations after a commodity price shock, while in the later period, the response is much less pronounced. The dampened response of materials and supplies inventories in the post-1983 period is consistent with the adoption of business practices that utilize technological and financial innovations to better isolate firms' supply and production chains from unanticipated movements in commodity prices. Differences in the dynamics of finished goods inventories are similar to those in the durable goods sector, with finished goods inventories buffering production from sales fluctuations more in the post-1983 period. 


\subsection{Inventory Adjustment Speeds}

In this section, we explicitly investigate if the speed with which inventories at different stages of fabrication revert to their target levels has increased in recent years. ${ }^{22}$ To that purpose, we estimate an error-correction model that incorporates both the long- and shortterm dynamics of inventory investment at different stages of fabrication. The model also allows for time-varying target inventory-sales ratios, because, as pointed out by a number of economists, the decline in the ratio of inventories to sales since the early 1980s is one key feature of aggregate inventory behavior consistent with improvements in inventory practices. The error-correction specification offers a convenient framework for addressing a question of whether or not these improvements in inventory practices are also evident in a more rapid adjustment of inventory stocks to their target levels.

\subsubsection{Empirical Model}

For each industry, we consider the following system of error-correction equations:

$$
\begin{aligned}
\Delta \ln H_{t}= & \alpha_{H}+\lambda_{H}\left[E\left(\ln \left[\frac{H}{S}\right]_{t}^{*} \mid \mathfrak{I}_{t-1}\right)-\ln \left[\frac{H}{S}\right]_{t-1}\right]+ \\
& \sum_{j=1}^{6} \beta_{H j} \Delta \ln H_{t-j}+\sum_{j=1}^{6} \gamma_{H j} \Delta \ln S_{t-j}+u_{H t} ; \\
\Delta \ln W_{t}= & \alpha_{W}+\lambda_{W}\left[E\left(\ln \left[\frac{W}{S}\right]_{t}^{*} \mid \mathfrak{I}_{t-1}\right)-\ln \left[\frac{W}{S}\right]_{t-1}\right]+ \\
& \sum_{j=1}^{6} \beta_{W j} \Delta \ln W_{t-j}+\sum_{j=1}^{6} \gamma_{W j} \Delta \ln S_{t-j}+u_{W t} ; \\
\Delta \ln M_{t}= & \alpha_{M}+\lambda_{M}\left[E\left(\ln \left[\frac{M}{S}\right]_{t}^{*} \mid \mathfrak{I}_{t-1}\right)-\ln \left[\frac{M}{S}\right]_{t-1}\right]+ \\
& \sum_{j=1} \beta_{M j} \Delta \ln M_{t-j}+\sum_{j=1}^{6} \gamma_{M j} \Delta \ln S_{t-j}+u_{M t},
\end{aligned}
$$

where $H_{t}$ denotes the real stock of finished goods inventories, $W_{t}$ the real stock of workin-progress inventories, $M_{t}$ the real stock of materials and supplies, and $S_{t}$ real sales in period $t$. The terms $\ln \left[\frac{H}{S}\right]_{t}^{*}, \ln \left[\frac{W}{S}\right]_{t}^{*}$, and $\ln \left[\frac{M}{S}\right]_{t}^{*}$ represent the time-varying "target" $(\log )$ inventory-sales ratio for finished goods, work-in-progress, and materials and supplies inventories, respectively, and $E\left(\cdot \mid \mathfrak{I}_{t-1}\right)$ is the expectation operator conditional on the information set $\mathfrak{I}_{t-1}$, containing all the information dated $t-1$ and earlier. The vector of random

\footnotetext{
${ }^{22}$ This section owes a great deal to the internal work on inventory dynamics by our Federal Reserve Board colleagues Rochelle Edge, Doug Elmendorf, Stacey Tevlin, and Peter Tulip.
} 
disturbances $\mathbf{u}_{t}=\left(u_{H t} u_{W t} u_{M t}\right)^{\top}$ is assumed to be serially uncorrelated with a mean of zero and an unrestricted covariance matrix.

Although (4.2.1) is not derived explicitly from an optimization problem, it can be thought of as a version of the flexible accelerator model introduced by Lovell (1961), extended to allow inventory adjustment to differ by the stage of fabrication. ${ }^{23}$ In that model, firms are assumed to balance the cost of straying from the inventory-sales ratios that are optimal in the absence of adjustment costs - the target ratios - against the cost of changing production. This assumption is consistent with the production smoothing dynamics evident in the impulse responses discussed in the previous section. As indicated by the expectation operators, this tradeoff is based not only on current inventory stocks, sales, and output, but also on the expected future paths of these variables. Lagged inventory investment affects current investment because past decisions are correlated with lagged output and altering production is costly. Past growth rates of sales enter the specification because they helps firms predict current and future sales and thus desired inventories. The parameters of interest, $\lambda_{H}, \lambda_{W}$, and $\lambda_{M}$, measure the speed of inventory stock adjustment to its target.

To make the model operational, we must specify the unobserved target inventory-sales ratios at each stage of fabrication. As discussed by Ramey and West (1999), for example, the target ratios are likely to depend on a number of factors, the most important being inventory holding costs, stockout costs, expected relative price changes, and properties of the exogenous shocks. While a complete structural model of inventory investment is beyond the scope of this paper, our focus - namely, changes in the rate of inventory adjustment over time - warrants the use of time-series filtering techniques to infer the target ratios. Specifically, the target inventory-sales ratios are estimated by a symmetric centered moving average filter:

$$
\ln \left[\frac{z}{S}\right]_{t}^{*}=\sum_{i=-k}^{k} \theta_{i} \ln \left[\frac{z}{S}\right]_{t-i} ; \quad z=H, W, M
$$

By appropriate choice of the moving average coefficients $\theta_{i}=\theta_{-i}, i=1,2, \ldots, k$, in (4.2.2), we can estimate the trend component of the inventory-sales ratio, which we then identify as the target ratio. In our specification, we use the Henderson moving average - a computationally tractable moving average with high series smoothing capabilities - to estimate the target inventory-sales ratios in (4.2.2); see Gourieroux and Monfort (1997) for a detailed

\footnotetext{
${ }^{23}$ As discussed by Ramey and West (1999), the error-correction equation underlying a flexible accelerator model can be derived from a standard linear-quadratic framework. By allowing dynamics to differ by stage of fabrication, the specification (4.2.1) has much in common with the model developed by Humphreys, Maccini, and Schuh (2001). We sacrifice some of their theoretical rigor in order to obtain an empirical model that can more easily encompass some of the low-frequency behavior of inventory-sales ratios.
} 
exposition. ${ }^{24}$

Given our assumptions, the estimation of (4.2.1) subject to (4.2.2) is straightforward. The terms dated $t, t+1, \ldots, t+k$ in the target ratios are replaced by their actual values, which transforms the serially uncorrelated disturbance vector $\mathbf{u}_{t}$ into a vector moving average process of order $k$. The induced moving average process is correlated with the explanatory variables in (4.2.1), necessitating the use of an instrumental variable estimation method. Because variables dated $t-k-1$ or earlier are in the information set $\mathfrak{I}_{t-1}$ and are uncorrelated with the transformed error term, they are valid instruments for standard GMM estimation (see Hansen (1982)).

Our choice of the Henderson moving average window $k$ for each industry is six months, and, accordingly, we use the logarithms of $H_{t-7}, \ldots, H_{t-12}, W_{t-7}, \ldots, W_{t-12}$, $M_{t-7}, \ldots, M_{t-12}$, and $S_{t-7}, \ldots, S_{t-12}$ as instruments. For each industry, we estimate the system of equations (4.2.1) subject to (4.2.2) using GMM in a SUR framework to take into account the correlation of error terms across equations. ${ }^{25}$ To make the results comparable to our previous analysis, we use the same two nonoverlapping sample periods - 1967:I-1978:XII and 1984:I-2000:XII - to estimate the model. Table 1a contains the estimates for the speed of adjustment coefficients in the durable goods industries, while those in the nondurable goods industries are shown in Table 1b. Each table also contains $p$-values for the industryspecific Wald test of the stability of the speed of adjustment coefficients between the two periods (see Andrews and Fair (1988)).

\subsubsection{Results}

Tables $1 \mathrm{a}$ and $2 \mathrm{~b}$ indicate that, in general, the error-correction specification (4.2.1)-(4.2.2) fits the data quite well in both sample periods. Inventory adjustment speeds for most industries are estimated with considerable precision and lie between 0 and 1, yielding economically plausible rates of trend reversion. Though not reported, Hansen's (1982) test of the over-identifying restrictions does not reject the orthogonality of the instruments in all cases; moreover, the stability of the over-identifying restrictions between the two periods is not rejected for every industry (see Hall and Sen (1999) for details). There are, however,

\footnotetext{
${ }^{24}$ Because our data are chain-weighted, real inventory-sales ratios in (4.2.2) have no clear meaning. Nominal inventory-sales ratios, by contrast, provide a better measure of inventory overhangs, because they can be interpreted as the "months supply" of inventories. Our focus in this exercise, however, is on the deviations of inventory-sales ratios from their targets. Although nominal and real inventory-sales ratios exhibit substantial differences in low frequency behavior, both nominal and real deviations from trends are very highly correlated. Moreover, the high correlation between real and nominal trend deviations is robust to a number of alternative commonly used detrending techniques.

${ }^{25}$ In addition, we impose restrictions that $\sum_{j=1}^{6} \beta_{H j}+\sum_{j=1}^{6} \gamma_{H j}=1, \sum_{j=1}^{6} \beta_{W j}+\sum_{j=1}^{6} \gamma_{W j}=1$, and $\sum_{j=1}^{6} \beta_{M j}+\sum_{j=1}^{6} \gamma_{M j}=1$, implying that in the steady state, sales and inventories at each stage of fabrication grow at a constant rate and that the inventory-sales ratios equal their targets.
} 
some important differences between the two sectors as well as the two sample periods, which we discuss in turn.

For a majority of durable goods industries (Table 1a), the estimated adjustment speeds for finished goods and work-in-progress inventories are appreciably higher in the post-1983 period. Compared with the pre-1979 period, the weighted average of the estimates of the error-correction parameters for finished goods is almost 50 percent higher in the post1983 period, implying a decline in the half-life of inventory deviations from 1.3 months to 0.7 months. In the case of work-in-progress inventories, the increase in adjustment speed is even more dramatic: The average error-correction parameter in the post-1983 period is three times as large as that in the earlier period, implying a decrease in the half-life of inventory deviations from about 5.0 months to 1.2 months. The faster adjustment of workin-progress and finished goods stocks is consistent with the impulse responses presented in the previous section, which displayed considerably more rapid trend reversion of finished goods and work-in-progress inventory-sales ratios in the post-1983 period.

For materials and supplies, by contrast, the pattern of inventory adjustment speeds between the two periods is quite different. Although point estimates indicate a notable increase in the rate of trend reversion for a number of industries (SICs 24, 25, 33, and 39 ), these industries, with the exception of SIC 33 (Primary Metal Industries), account for a small share of inventory of materials and supplies in the durable goods sector. For the remaining industries, the estimates of the adjustment parameters are considerably smaller in the post-1983 period; indeed, for the largest industries in the sector (SICs 34-38), the estimates of the adjustment speeds for materials and supplies are economically slow and statistically not different from zero. As a result, the average inventory adjustment speed for the sector as a whole is about one-fifth lower in the post-1983 period.

At first glance, a slower adjustment speed for materials and supplies in the post-1983 period may seem at odds with the findings of the previous section, which showed a considerably quicker trend reversion of the inventory-sales ratio for materials and supplies in that period. However, because the objective of JIT inventory management is to keep materials and supplies inventories at a minimum and to gauge demand by waiting until the last possible moment to place an order, much of the adjustment of inventories to shocks is registered in the target. Consequently, a switch from forecast-based purchases implicit in the error-correction specification to just-in-time purchases is consistent with both a more rapid response of materials and supplies to shocks affecting sales as well as a slower dissipation of inventory imbalances.

Turning to the nondurable goods sector (Table $1 \mathrm{~b}$ ), the estimates of the inventory adjustment speeds across the different stages of fabrication generally indicate faster trend reversion in the post-1983 period. One notable exception is SIC 29 (Petroleum and Coal 
Products), an industry that experienced a statistically significant decline in all three coefficients between the two periods. As was the case in the durable goods sector, the largest increases in the estimated adjustment speeds are for finished goods and work-in-progress inventories, where the average coefficient rose 50 percent and 60 percent, respectively. This increase implies a reduction in the half-life of inventory deviations from 1.5 to 0.8 months for finished goods and a drop from 1.3 to 0.6 months for work-in-progress inventories. The increase in the rate of trend reversion for inventory of materials and supplies, by contrast, is more modest, with the average half-life of inventory imbalances decreasing from 1.3 to 1.0 months between the two sample periods.

\subsection{Discussion}

From the results of the previous two sections, we draw three principal conclusions:

1. In both the durable and nondurable goods sectors, inventory adjustment at all stages of fabrication has become more rapid since the mid-1980s.

2. The changes in the adjustment of finished goods and work-in-progress inventories since the mid-1980s are consistent with greater production smoothing by manufacturers, resulting in less variable output.

3. The changes in inventory adjustment appear largely to reflect changes in the aggregate economic environment.

Our first conclusion is supported by the finding that the responses of inventories and inventory-sales ratios to monetary policy and commodity price shocks in the post-1983 period are quicker and less persistent than those in the pre-1979 period. Moreover, finished goods and work-in-progress inventories adjust markedly faster to eliminate inventory imbalances in the post-1983 period. Adjustment speeds for materials and supplies, by contrast, appear not to have increased materially since the mid-1980s. However, the combination of a more rapid response of materials and supplies to aggregate shocks and a relatively low estimate of the adjustment speed likely reflects that, under JIT practices, much of the materials and supplies adjustment occurs through changes in the target level of inventories. These results are thus consistent with common conceptions that firms' improved control of production processes and delivery systems has led to the more rapid identification and resolution of inventory imbalances.

Several pieces of evidence support our second conclusion. First, according to our VAR model, the response of inventories has become more countercyclical relative to that of sales. Second, the error correction model - essentially a production-smoothing model - generally fits the data well for finished goods and work-in-progress inventories, and the estimated 
adjustment speeds for these two types of inventories have increased notably in the post1983 period. Taken together, these results suggest that inventory behavior has contributed to lower output volatility since the mid-1980s.

While the first two conclusions support the inventory conjecture, our last point asserts that improved inventory management has likely played a supporting, rather than a primary, role in moderating the volatility of manufacturing output. We base this conclusion on two results from the VAR model: (1) the response of aggregate economic activity-private employment in our case - to the monetary policy and commodity price shocks; and (2) the response of the Fed funds rate, the monetary policy instrument, to commodity price shocks.

As discussed previously, the response of employment to monetary policy and commodity price shocks differs considerably between the two periods. In the post-1983 period, employment responded more immediately to the monetary policy shock, but it had a smaller response to the commodity price shock. Because the VAR model allows for complementarities, these differences in the employment response influence the differences in the responses of industry-level sales and inventories between the two periods. Accordingly, the differences in inventory dynamics between the two periods may be due to changes in the macroeconomic environment.

The significant difference in the response of the Fed funds rate to commodity price shocks suggest that one such change may be a prompter and more aggressive response of monetary policy to incipient inflationary pressures in the post-1983 period, evidenced by the larger response of the Fed funds rate to a commodity price shock. This result is also consistent with recent studies that have estimated forward-looking policy reaction functions and found a substantially stronger policy response to expected inflation following the appointment of Paul Volcker as the Chairman of the Federal Reserve in 1979; see, for example, Clarida, Gali, and Gertler (2000) and Boivin and Giannoni (2002). It also is consistent with Orphanides' (2003) characterization of the change in monetary policy during the early 1980s, in which the Federal Open Market Committee slowly abandoned its efforts to "fine tune" the economy, focusing instead on its long-term goal of price stability.

In either case, these operational shifts in the conduct of monetary policy may explain the changes in the estimated responses of aggregate employment and industry sales. If market participants perceive the Federal Reserve as adhering consistently and credibly to its goal of price stability, then altering the stance of monetary policy signals changing inflationary pressures, which ceteris paribus, should prompt quick and more decisive responses by economic agents. In addition, a prompt and decisive response of monetary policy to the inflationary consequences of supply shocks should lead to those shocks having a lesser effect on economic activity. 
Given these changes in the behavior of aggregate variables, it is then not clear that improvements in inventory management have played a primary role in lowering aggregate output volatility. Rather, the increase in the extent with which inventories buffer production from demand shocks may be a consequence of less variable sales, as evident in the response of shipments in the post-1983 period. Under a less activist monetary policy, for example, the benefits of maintaining stable production - in terms of lower adjustment costs - increase, because firms expect that their sales will experience less persistent fluctuations after a monetary policy shock. The incentive to smooth production through inventories also increases, because the holding costs associated with additional stock accumulation are limited by the shorter period of "excess" inventories. The deepening of and the increased access to capital markets over the past two decades may have also contributed to the reduction in inventory holding costs by lessening the sensitivity of inventory investment to business cash flow. Therefore, the changes in inventory responses, rather than being a fundamental factor behind the decline in GDP volatility, instead may have been a consequence of changes in other features of the economy.

Nevertheless, our analysis does not deny that improved inventory management may have played an important complementary role in the volatility decline. If aggregate factors such as better monetary policy and smaller shocks have resulted in more predictable final sales, then businesses, faced with falling costs of information technology, will likely have a greater incentive to implement integrated physical distribution management of production and inventories, which in turn could lead to a further decline in volatility. It is unlikely, however, that these developments have eliminated the inventory cycle. In particular, when in 200102 aggregate uncertainty increased, sharp and sudden inventory liquidation, especially in the manufacturing sector, significantly exacerbated the economic contraction.

Overall, our analysis of the inventory adjustment process provides limited support for the inventory conjecture, a conclusion that falls between the two extremes on this question. While we do not assign as prominent a role for inventory management as do MPQ or Kahn, McConnell, and Perez-Quiros (2002), we have found convincing evidence indicating that inventory behavior has become more production-smoothing since the mid-1980s. But in the end, much of the change in inventory dynamics appears to be a consequence of changes in the aggregate environment, most notably the conduct of monetary policy.

\section{Concluding Remarks}

Our main goal in this paper was to examine if and how manufacturing inventory dynamics have changed since the mid-1980s, a period marked by a pronounced step-down in the volatility of aggregate economic activity. Our results indicate that although inventory be- 
havior has changed in a manner consistent with the inventory conjecture, it is difficult to attribute most of the reduction in GDP volatility to changes in inventory management, for several reasons. First, the decline in manufacturing production volatility appears to be driven almost entirely by a reduction in the volatility of shipments. Second, a significant decline in the volatility of materials and supplies that started in the mid-1970s has moderated the variability of total inventory investment, but there is little evidence supporting similar reductions in the volatility of inventories at other stages of fabrications in the mid-1980s. Third, even though the responses of inventories to aggregate shocks and inventory adjustment speeds have changed in a manner consistent with inventories having a greater role in buffering sales fluctuations, these changes appear to reflect changes in the dynamics of aggregate variables and industry sales. Therefore, the changes in inventory behavior since the mid-1980s are more likely a consequence of changes in the macroeconomic environment and thus have had a complementary, rather than leading role, in the decline of aggregate output volatility.

Our analysis focused on the manufacturing sector, but our results have implications for inventories in the rest of the economy. Because of increased global competition, many companies have moved from "in-house" inventory management to vendor-managed inventory and have outsourced some manufacturing to other firms in an attempt to boost profit margins. Indeed, according to a number of industry reports, one of the best methods for controlling inventories is to outsource various segments of production to contract firms, which complete all the manufacturing steps and even carry the financial burden of the inventory until the finished product is delivered. This transformation of production and distribution has resulted in a much more complex supply chain system that integrates manufacturers, suppliers, and customers, and in which management of wholesale and retail trade inventories may be an important component of any changes in the transmission of aggregate shocks. Thus, understanding more about the role of trade inventories in the overall process of economic adjustment remains one important issue left for future research.

\section{References}

Ahmed, S., A. Levin, and B. A. Wilson (2001): "Recent U.S. Macroeconomic Stability: Good Policy, Good Practices, or Good Luck?," Mimeo, Federal Reserve Board.

Allen, D. S. (1995): "Changes in Inventory Management and the Business Cycle," Review, Federal Reserve Bank of St. Louis, 4, 17-33.

Andrews, D. W. K., And R. FAIR (1988): "Inference in Econometric Models With Structural Change," Review of Economic Studies, 55, 615-640. 
BARTh III, M. J., And V. A. RAmey (2001): "The Cost Channel of Monetary Transmission," in NBER Macroeconomics Annual, ed. by B. S. Bernanke, and K. Rogoff, vol. 16. The MIT Press, Cambridge, MA.

Bechter, D. M., and S. Stanley (1992): "Evidence of Improved Inventory Control," Federal Reserve Bank of Richmond Economic Review, 1, 3-12.

Bernanke, B. S., and M. Gertler (1995): "Inside the Black Box: The Credit Channel of Monetary Policy Transmission," Journal of Economic Perspectives, 9, 27-48.

Blanchard, O. J., and N. Kiyotaki (1987): "Monopolistic Competition and the Effects of Aggregate Demand," American Economic Review, 77, 647-666.

Blanchard, O. J., and J. Simon (2001): "The Long and Large Decline in U.S. Output Volatility," Brookings Papers on Economic Activity, 1, 67-127.

Blinder, A. S. (1986): "Can the Production Smoothing Model of Inventories be Saved?," Quarterly Journal of Economics, 101, 431-454.

Boivin, J., And M. Giannoni (2002): "Has Monetary Policy Become Less Powerful?," Mimeo, Federal Reserve Bank of New York.

Clarida, R., J. Galí, and M. Gertler (2000): "Monetary Policy Rules and Macroeconomic Stability: Evidence and Some Theory," Quarterly Journal of Economics, 115, $147-180$.

Cooper, R., And A. John (1988): "Coordinating Coordination Failures in Keynesian Models," Quarterly Journal of Economics, 103, 441-463.

Feroli, M. (2002): "An Equilibrium Model of Inventories with Investment-Specific Technical Change," Mimeo, Dept. of Economics, New York University.

Filardo, A. J. (1995): "Recent Evidence on the Muted Inventory Cycle," Federal Reserve Bank of Kansas City Economic Review, 2, 27-43.

Gourieroux, C., And A. Monfort (1997): Time Series and Dynamic Models. Cambridge University Press, Cambridge, UK.

Hall, A., And A. Sen (1999): "Structural Stability Testing in Models Estimated by Generalized Method of Moments," Journal of Business and Economic Statistics, 17, 335348.

Hamilton, J. D. (1994): Time Series Analysis. Princeton University Press, Princeton, NJ.

Hansen, L. P. (1982): "Large Sample Properties of Generalized Method of Moment Estimators," Econometrica, 50, 1029-1054.

Huber, P. J. (1981): Robust Statistics. John Wiley, New York, NY. 
Humphreys, B. J., L. J. Maccini, and S. Schuh (2001): "Input and Output Inventories," Journal of Monetary Economics, 47, 135-164.

Irvine, F. O., And S. Schuh (2003): "Inventory Investment and Output Volatility," Mimeo, Federal Reserve Bank of Boston.

Ivanov, V., And L. Kilian (2001): "A Practitioner's Guide to Lag-Order Selection for Vector Autoregressions," Mimeo, Dept. of Economics, University of Michigan.

Kahn, J. A., M. M. McConnell, and G. Perez Quiros (2001): "Inventories and the Information Revolution: Implications for Output Volatility," Mimeo, Federal Reserve Bank of New York.

(2002): "On the Causes of the Increased Stability of the U.S. Economy," Economic Policy Review, Federal Reserve Bank of New York, 8(1), 183-202.

KiLIAn, L. (2001): "Impulse Response Analysis in Vector Autoregressions with Unknown Lag Order," Journal of Forecasting, 20, 161-179.

Kim, C.-J., C. Nelson, And J. Piger (2001): "The Less Volatile U.S. Economy: A Bayesian Investigation of Timing, Breadth, and Potential Explanations," Mimeo, Federal Reserve Board.

Lambert, D. M., And J. T. Mentzer (1978): "Is Integrated Physical Distribution Management a Reality?," Journal of Business Logistics, 2, 18-33.

LitTle, J. S. (1992): "Changes in Inventory Management: Implications for the U.S. Recovery," New England Economic Review, November/December, 37-65., Federal Reserve Bank of Boston.

Lovell, M. (1961): "Manufacturers Inventories, Sales Expectations, and the Acceleration Principle," Econometrica, 39, 293-314.

McConnell, M. M., P. C. Mosser, and G. Perez Quiros (1999): "A Decomposition of the Increased Stability of GDP Growth," Current Issues in Economics and Finance, Federal Reserve Bank of New York, 5(13).

McConnell, M. M., And G. Perez Quiros (2000): "Output Fluctuations in the United States: What Has Changed Since the Early 1980s?," American Economic Review, 90, $1464-1476$.

Morgan, D. P. (1991): "Will Just-In-Time Inventory Techniques Dampen Recessions?," Federal Reserve Bank of Kansas City Economic Review, 2, 21-33.

Newey, W. K., and K. D. West (1987): "A Simple, Positive Semi-Definite, Heteroskedasticity and Autocorrelation Consistent Covariance Matrix," Econometrica, 55, 703-708.

Orphanides, A. (2003): "Monetary Policy Rules, Macroeconomic Stability and Inflation: A View from the Trenches," Forthcoming, Journal of Money, Credit, and Banking. 
Ramey, V. A., And D. J. Vine (2001): "Tracking the Source of the Decline in GDP Volatility: An Analysis of the Automobile Industry," Mimeo, Dept. of Economics, University of California San Diego.

Ramey, V. A., And K. D. West (1999): "Inventories," in Handbook of Macroeconomics, ed. by J. B. Taylor, and M. Woodford, pp. 863-923. North-Holland, Elsevier, New York, NY.

Rousseeuw, P. J., And C. Croux (1993a): "Alternatives to Median Absolute Deviation," Journal of the American Statistical Association, 88, 1273-1283.

(1993b): "The Bias of k-Step M-estimators," Statistics and Probability Letters, 20, 411-420.

Sensier, M., And D. VAn DiJK (2001): "Short-Term Volatility versus Long-Term Growth: Evidence in U.S. Macroeconomic Time Series," University of Manchester, Centre for Growth and Business Cycle Research Discussion Paper No. 008, February.

Stock, J. H., And M. W. Watson (2002): "Has the Business Cycle Changed and Why?," Forthcoming NBER Macroeconomics Annual.

Warnock, C. M. V., And F. E. Warnock (2000): "The Declining Volatility of U.S. Employment: Was Arthur Burns Right?," International Finance Discussion Papers, Federal Reserve Board.

Whelan, K. (2000): "A Guide to the Use of Chain-Aggregated NIPA Data," Finance and Economics Discussion Series Paper No. 35, Federal Reserve Board. 
Table 1a: Inventory Adjustment Speeds

\begin{tabular}{|c|c|c|c|c|c|c|c|}
\hline \multicolumn{8}{|c|}{ Manufacturing Durable Goods Sector } \\
\hline \multirow[b]{2}{*}{$\mathrm{SIC}$} & \multirow[b]{2}{*}{$\operatorname{Pr}>W^{a}$} & \multicolumn{3}{|c|}{ Sample: 1967:I-1978:XII } & \multicolumn{3}{|c|}{ Sample: 1984:I-2000:XII } \\
\hline & & $\lambda_{H}$ & $\lambda_{W}$ & $\lambda_{M}$ & $\lambda_{H}$ & $\lambda_{W}$ & $\lambda_{M}$ \\
\hline 24 & 0.87 & $\begin{array}{c}0.55 \\
(0.12)\end{array}$ & $\begin{array}{c}0.61 \\
(0.15)\end{array}$ & $\begin{array}{c}0.34 \\
(0.13)\end{array}$ & $\begin{array}{c}0.63 \\
(0.12)\end{array}$ & $\begin{array}{c}0.64 \\
(0.13)\end{array}$ & $\begin{array}{c}0.45 \\
(0.10)\end{array}$ \\
\hline 25 & 0.20 & $\begin{array}{c}0.66 \\
(0.10)\end{array}$ & $\begin{array}{c}0.50 \\
(0.12)\end{array}$ & $\begin{array}{c}0.43 \\
(0.10)\end{array}$ & $\begin{array}{c}0.96 \\
(0.22)\end{array}$ & $\begin{array}{c}0.76 \\
(0.21)\end{array}$ & $\begin{array}{c}0.82 \\
(0.20)\end{array}$ \\
\hline 32 & 0.02 & $\begin{array}{c}0.62 \\
(0.13)\end{array}$ & $\begin{array}{c}0.52 \\
(0.17)\end{array}$ & $\begin{array}{c}0.35 \\
(0.09)\end{array}$ & $\begin{array}{c}0.21 \\
(0.11)\end{array}$ & $\begin{array}{c}0.51 \\
(0.17)\end{array}$ & $\begin{array}{c}0.06 \\
(0.15)\end{array}$ \\
\hline 33 & $<.01$ & $\begin{array}{c}0.11 \\
(0.06)\end{array}$ & $\begin{array}{c}0.10 \\
(0.03)\end{array}$ & $\begin{array}{l}-0.02 \\
(0.05)\end{array}$ & $\begin{array}{c}0.51 \\
(0.11)\end{array}$ & $\begin{array}{c}0.32 \\
(0.13)\end{array}$ & $\begin{array}{c}0.49 \\
(0.14)\end{array}$ \\
\hline 34 & 0.01 & $\begin{array}{c}0.64 \\
(0.11)\end{array}$ & $\begin{array}{c}0.21 \\
(0.13)\end{array}$ & $\begin{array}{c}0.97 \\
(0.09)\end{array}$ & $\begin{array}{c}0.33 \\
(0.16)\end{array}$ & $\begin{array}{c}0.55 \\
(0.17)\end{array}$ & $\begin{array}{c}0.38 \\
(0.25)\end{array}$ \\
\hline 35 & 0.17 & $\begin{array}{c}0.47 \\
(0.07)\end{array}$ & $\begin{array}{c}0.32 \\
(0.06)\end{array}$ & $\begin{array}{l}0.39 \\
0.08\end{array}$ & $\begin{array}{c}0.64 \\
(0.15)\end{array}$ & $\begin{array}{c}0.58 \\
(0.13)\end{array}$ & $\begin{array}{c}0.10 \\
(0.17)\end{array}$ \\
\hline 36 & 0.33 & $\begin{array}{c}0.40 \\
(0.08)\end{array}$ & $\begin{array}{c}0.21 \\
(0.10)\end{array}$ & $\begin{array}{c}0.33 \\
(0.06)\end{array}$ & $\begin{array}{c}0.61 \\
(0.19)\end{array}$ & $\begin{array}{c}0.35 \\
(0.10)\end{array}$ & $\begin{array}{c}0.18 \\
(0.16)\end{array}$ \\
\hline 37 & 0.01 & $\begin{array}{c}0.29 \\
(0.13)\end{array}$ & $\begin{array}{c}0.01 \\
(0.04)\end{array}$ & $\begin{array}{c}0.07 \\
(0.13)\end{array}$ & $\begin{array}{c}1.18 \\
(0.54)\end{array}$ & $\begin{array}{c}0.37 \\
(0.10)\end{array}$ & $\begin{array}{c}0.03 \\
(0.12)\end{array}$ \\
\hline 38 & 0.38 & $\begin{array}{c}0.58 \\
(0.18)\end{array}$ & $\begin{array}{c}0.11 \\
(0.11)\end{array}$ & $\begin{array}{c}0.24 \\
(0.11)\end{array}$ & $\begin{array}{c}0.39 \\
(0.15)\end{array}$ & $\begin{array}{c}0.43 \\
(0.22)\end{array}$ & $\begin{array}{c}0.13 \\
(0.14)\end{array}$ \\
\hline \multirow[t]{3}{*}{39} & 0.01 & $\begin{array}{c}0.27 \\
(0.06)\end{array}$ & $\begin{array}{c}0.16 \\
(0.09)\end{array}$ & $\begin{array}{c}0.19 \\
(0.06)\end{array}$ & $\begin{array}{c}0.60 \\
(0.16)\end{array}$ & $\begin{array}{c}0.36 \\
(0.37)\end{array}$ & $\begin{array}{c}0.73 \\
(0.24)\end{array}$ \\
\hline & & \multicolumn{3}{|c|}{ Weighted Average ${ }^{b}$} & \multicolumn{3}{|c|}{ Weighted Average } \\
\hline & & 0.42 & 0.13 & 0.32 & 0.60 & 0.43 & 0.25 \\
\hline
\end{tabular}

Notes: The dependent variables in the 3-equation SUR system are the log-difference of finished goods inventories $\left(\Delta \ln H_{t}\right)$, the log-difference of work-in-progress inventories $\left(\Delta \ln W_{t}\right)$, and the $\log$-difference of materials \& supplies inventories $\left(\Delta \ln M_{t}\right)$. All variables are in real (chain-weighted, 1996=100) terms. Entries in the table are the GMM estimates of the speed of adjustment parameters: $\lambda_{H}=$ speed of adjustment of finished goods inventories; $\lambda_{W}=$ speed of adjustment of work-in-progress inventories; and $\lambda_{M}=$ speed of adjustment of materials \& supplies inventories. Heteroscedasticity- and autocorrelation-consistent asymptotic standard errors are reported parentheses and were computed according to Newey and West (1987) with the bandwidth parameter equal to six.

${ }^{a} p$-value for the Wald test of null hypothesis that the speed of adjustment coefficients are equal across the two sample periods. The $W$-statistic is distributed as $\chi^{2}$ with 3 degrees of freedom.

${ }^{b}$ Average estimate of the speed of adjustment coefficient across durable goods industries, weighted by the corresponding industry-specific average shares of inventories over the sample period. 
Table 1b: Inventory Adjustment Speeds

\begin{tabular}{|c|c|c|c|c|c|c|c|}
\hline \multicolumn{8}{|c|}{ Manufacturing Nondurable Goods Sector } \\
\hline \multirow[b]{2}{*}{$\mathrm{SIC}$} & \multirow[b]{2}{*}{$\operatorname{Pr}>W^{a}$} & \multicolumn{3}{|c|}{ Sample: 1967:I-1978:XII } & \multicolumn{3}{|c|}{ Sample: 1984:I-2000:XII } \\
\hline & & $\lambda_{H}$ & $\lambda_{W}$ & $\lambda_{M}$ & $\lambda_{H}$ & $\lambda_{W}$ & $\lambda_{M}$ \\
\hline \multirow[t]{2}{*}{20} & 0.30 & 0.22 & 0.32 & 0.42 & 0.56 & 0.61 & 0.75 \\
\hline & & $(0.20)$ & $(0.31)$ & $(0.12)$ & $(0.21)$ & $(0.18)$ & $(0.21)$ \\
\hline \multirow[t]{2}{*}{22} & $<.01$ & 0.49 & 0.18 & 0.33 & 0.41 & 1.28 & 0.72 \\
\hline & & $(0.09)$ & $(0.11)$ & $(0.10)$ & $(0.14)$ & $(0.21)$ & $(0.18)$ \\
\hline \multirow[t]{2}{*}{23} & $<.01$ & 0.46 & 0.29 & 0.66 & 0.37 & 0.81 & 0.13 \\
\hline & & $(0.12)$ & $(0.17)$ & $(0.13)$ & $(0.32)$ & $(0.19)$ & $(0.13)$ \\
\hline \multirow[t]{2}{*}{26} & 0.43 & 0.49 & 0.88 & 0.63 & 0.44 & 0.58 & 0.51 \\
\hline & & $(0.08)$ & $(0.16)$ & $(0.11)$ & $(0.09)$ & $(0.14)$ & $(0.10)$ \\
\hline \multirow[t]{2}{*}{27} & $<.01$ & 0.36 & 0.71 & 0.41 & 1.17 & 1.12 & 0.64 \\
\hline & & $(0.12)$ & $(0.20)$ & $(0.10)$ & $(0.18)$ & $(0.20)$ & $(0.17)$ \\
\hline \multirow[t]{2}{*}{28} & 0.46 & 0.54 & 0.37 & 0.38 & 0.72 & 0.35 & 0.44 \\
\hline & & $(0.03)$ & $(0.15)$ & $(0.12)$ & $(0.11)$ & $(0.15)$ & $(0.12)$ \\
\hline \multirow[t]{2}{*}{29} & 0.01 & 0.30 & 0.83 & 0.64 & 0.14 & 0.48 & 0.15 \\
\hline & & $(0.15)$ & $(0.08)$ & $(0.13)$ & $(0.12)$ & $(0.16)$ & $(0.12)$ \\
\hline \multirow[t]{2}{*}{30} & $<.01$ & 0.22 & 0.02 & -0.07 & 0.31 & 0.60 & 0.38 \\
\hline & & $(0.06)$ & $(0.10)$ & $(0.16)$ & $(0.12)$ & $(0.14)$ & $(0.13)$ \\
\hline \multirow[t]{4}{*}{31} & 0.06 & 0.45 & 0.28 & 0.48 & 0.54 & 0.83 & 0.49 \\
\hline & & $(0.17)$ & $(0.15)$ & $(0.16)$ & $(0.17)$ & $(0.14)$ & $(0.11)$ \\
\hline & & \multicolumn{3}{|c|}{ Weighted Average } & \multicolumn{3}{|c|}{ Weighted Average } \\
\hline & & 0.37 & 0.41 & 0.42 & 0.56 & 0.68 & 0.51 \\
\hline
\end{tabular}

Notes: The dependent variables in the 3-equation SUR system are the log-difference of finished goods inventories $\left(\Delta \ln H_{t}\right)$, the log-difference of work-in-progress inventories $\left(\Delta \ln W_{t}\right)$, and the log-difference of materials \& supplies inventories $\left(\Delta \ln M_{t}\right)$. All variables are in real (chain-weighted, 1996=100) terms. SIC 21 (Tobacco \& Related Products) is omitted from the analysis because of suspect data. Entries in the table are the GMM estimates of the speed of adjustment parameters: $\lambda_{H}=$ speed of adjustment of finished goods inventories; $\lambda_{W}=$ speed of adjustment of work-in-progress inventories; and $\lambda_{M}=$ speed of adjustment of materials \& supplies inventories. Heteroscedasticity- and autocorrelation-consistent asymptotic standard errors are reported parentheses and were computed according to Newey and West (1987) with the bandwidth parameter equal to six.

${ }^{a} p$-value for the Wald test of null hypothesis that the speed of adjustment coefficients are equal across the two sample periods. The $W$-statistic is distributed as $\chi^{2}$ with 3 degrees of freedom.

${ }^{b}$ Average estimate of the speed of adjustment coefficient across durable goods industries, weighted by the corresponding industry-specific average shares of inventories over the sample period. 


\section{Appendix}

\section{- Manufacturing Durable Goods Sector}

1. SIC 24: Lumber and Wood Products

2. SIC 25: Furniture and Fixtures

3. SIC 32: Stone, Clay, and Glass Products

4. SIC 33: Primary Metal Industries

5. SIC 34: Fabricated Metal Products

6. SIC 35: Industrial Machinery and Equipment

7. SIC 36: Electronic and Other Electric Equipment

8. SIC 37: Transportation Equipment

9. SIC 38: Instruments and Related Products

10. SIC 39: Miscellaneous Durable Goods

- Manufacturing Nondurable Goods Sector

1. SIC 20: Food and Kindred Products

2. SIC 21: Tobacco and Related Products

3. SIC 22: Textile Mill Products

4. SIC 23: Apparel and Other Textile Products

5. SIC 26: Paper and Allied Products

6. SIC 27: Printing and Publishing

7. SIC 28: Chemicals and Allied Products

8. SIC 29: Petroleum and Coal Products

9. SIC 30: Rubber and Miscellaneous Plastic Products

10. SIC 31: Leather Products 
Figure 1

\section{Volatility of Output, Sales, and Inventory Investment}

\section{Manufacturing Durable Goods Sector}

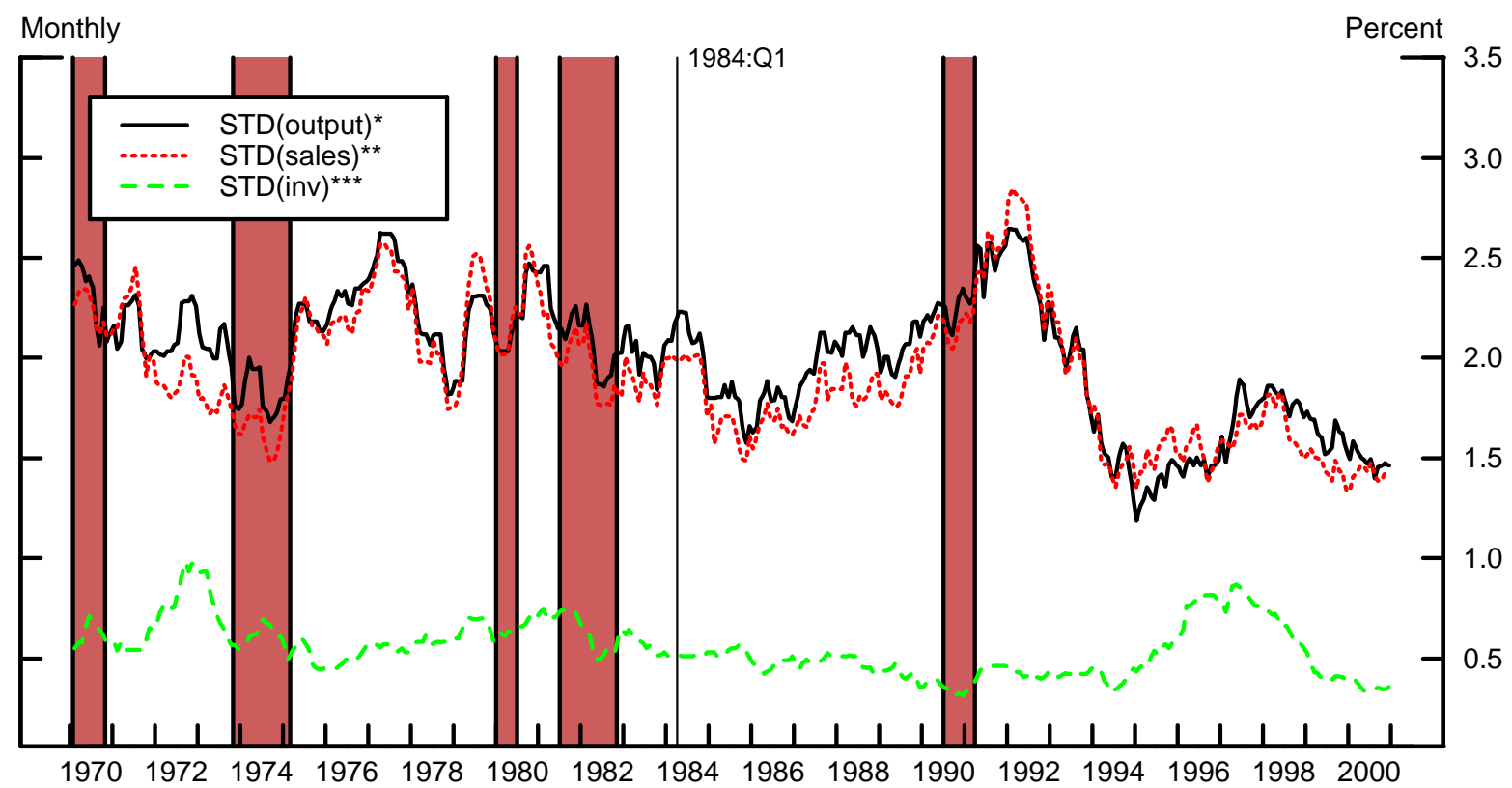

Note: The vertical line at 1984:Q1 marks the estimated date of volatility reduction for durable goods GDP.

\section{Manufacturing Nondurable Goods Sector}

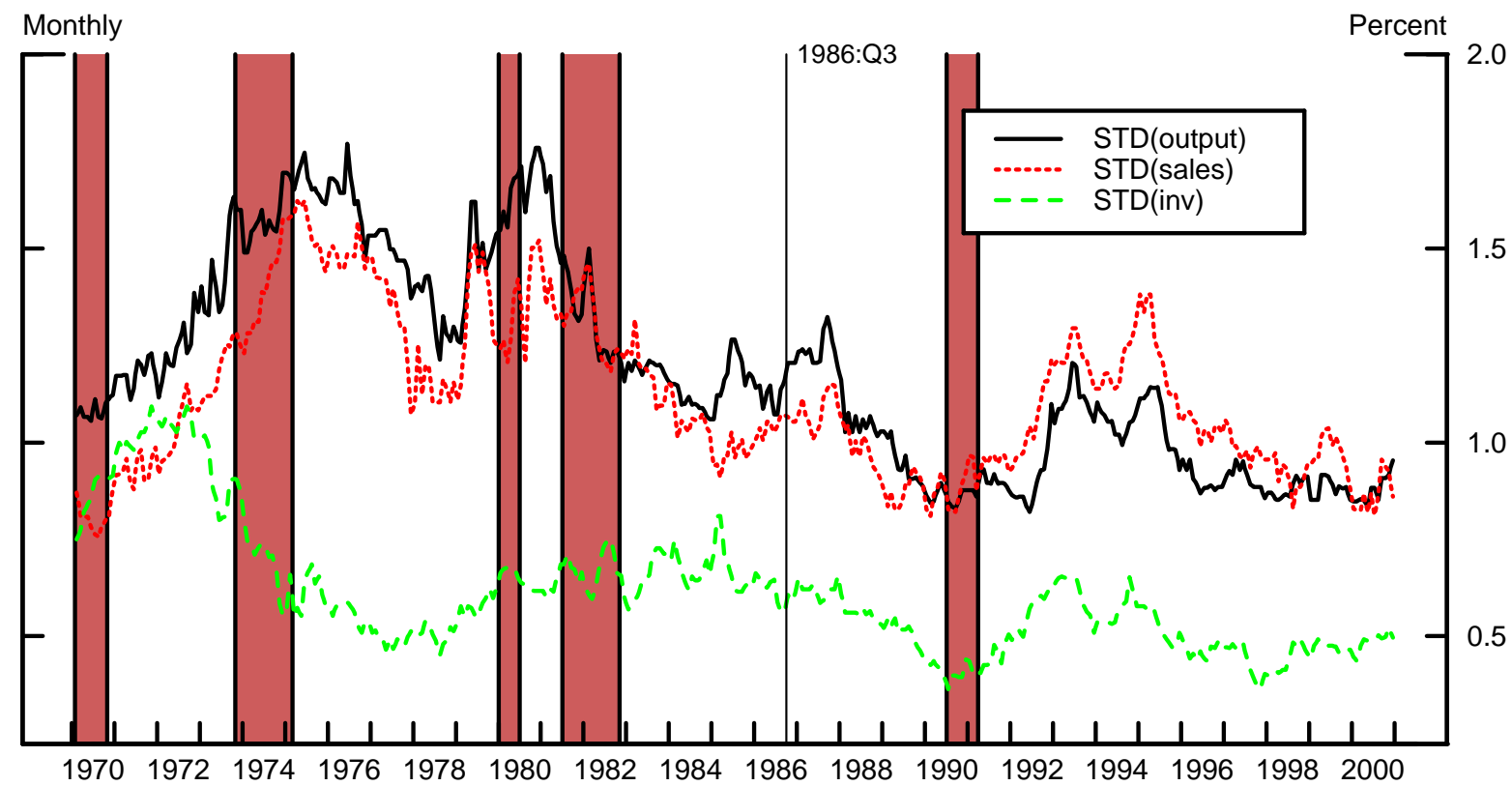

Note: The vertical line at 1986:Q3 marks the estimated date of volatility reduction for nondurable goods GDP.

* STD(output) denotes a rolling robust estimate of the standard deviation of the growth rate of output.

** STD(sales) denotes a rolling robust estimate of the standard deviation of the growth contribution of sales.

*** STD(inv) denotes a rolling robust estimate of the standard deviation of the growth contribution of inventory investment. 
Figure 2

\title{
Inventory Investment and Sales Correlations
}

\author{
Manufacturing Durable Goods Sector
}

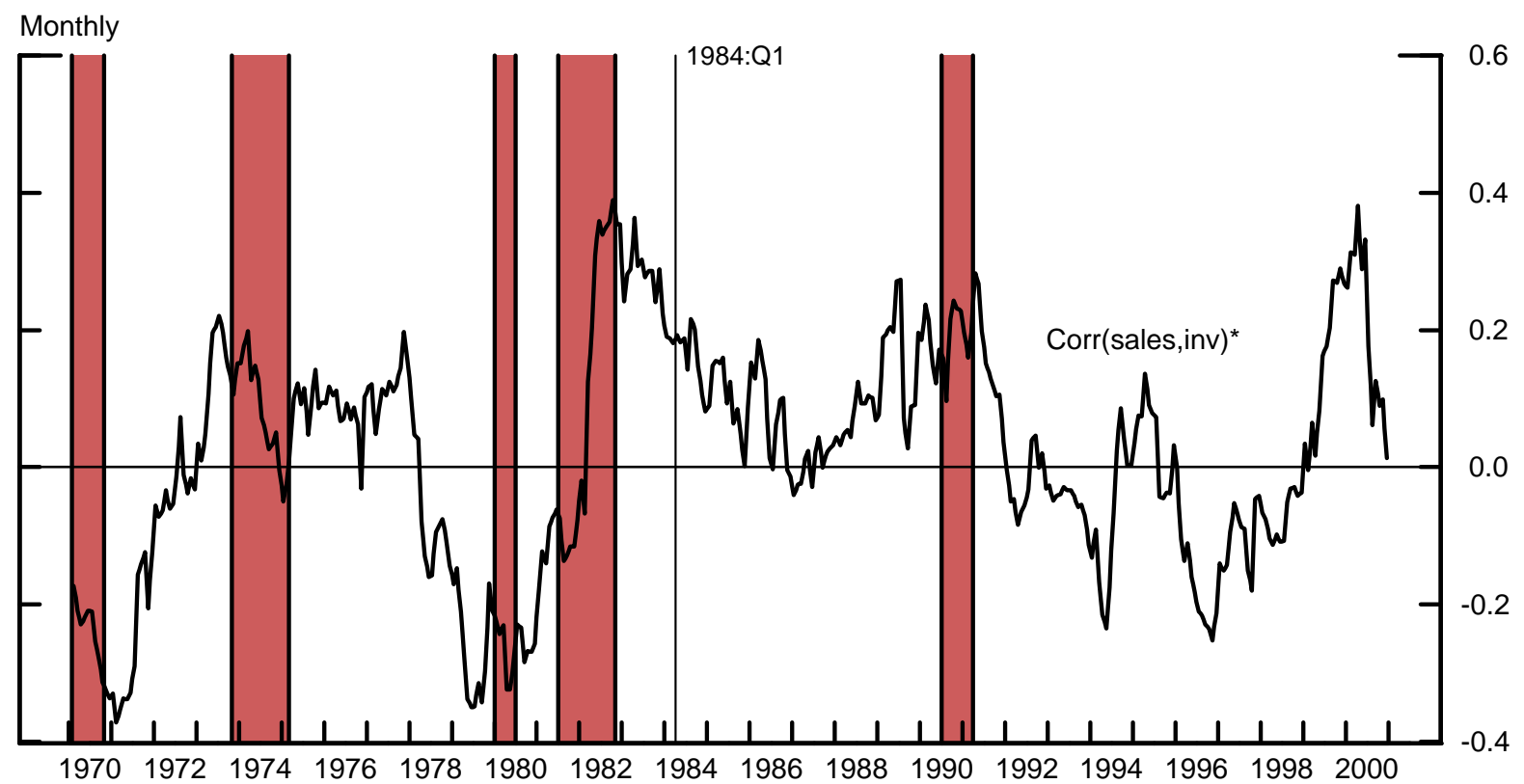

Note: The vertical line at 1984:Q1 marks the estimated date of volatility reduction for durable goods GDP.

\section{Manufacturing Nondurable Goods Sector}

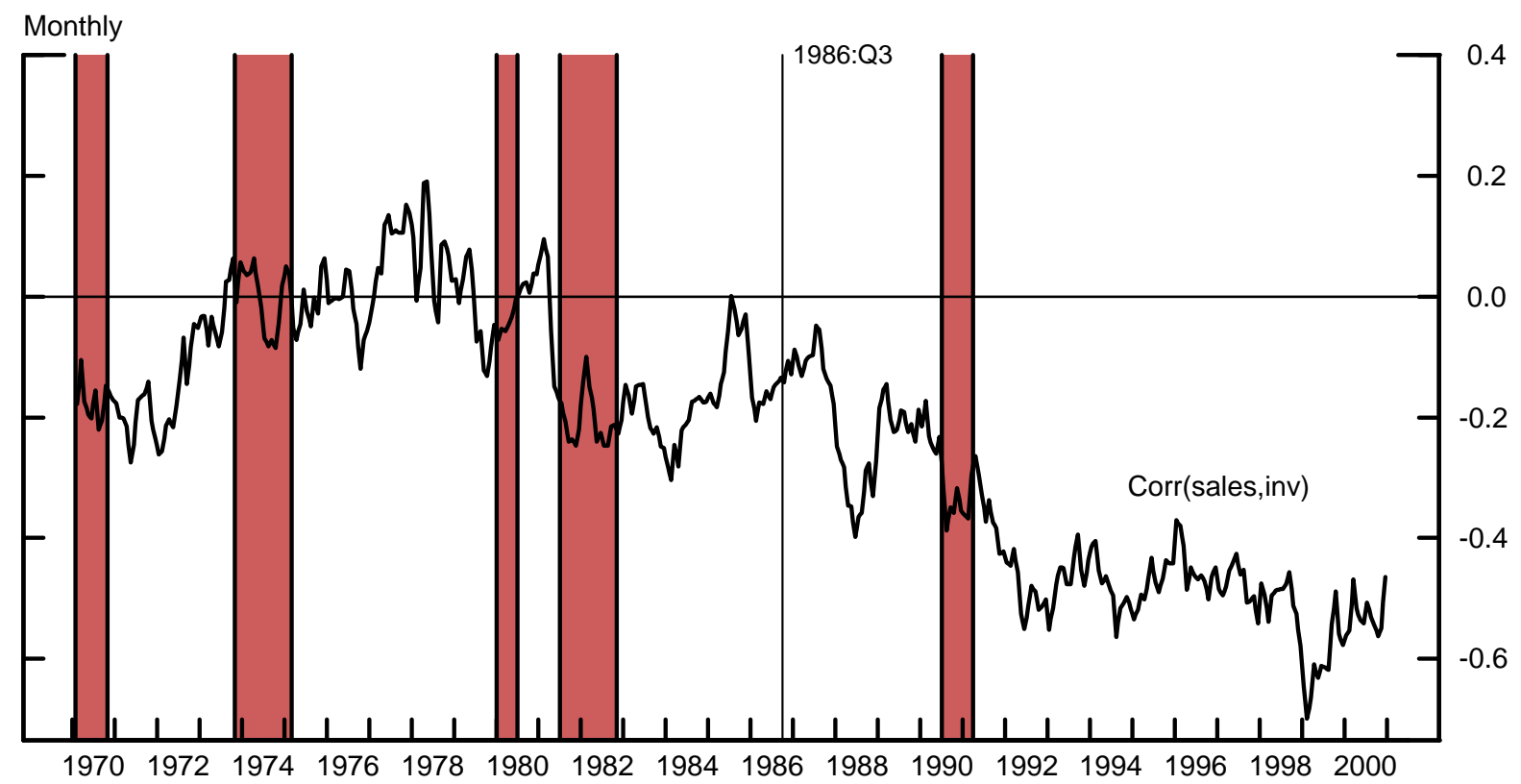

Note: The vertical line at 1986:Q3 marks the estimated date of volatility reduction for nondurable goods GDP.

* Corr(sales,inv) denotes a rolling 5-percent trimmed correlation between the growth contribution of sales and the growth contribution of inventory investment. 
Figure 3a

\section{Inventory Volatility in Manufacturing Durable Goods Sector}

\section{Total Inventories}

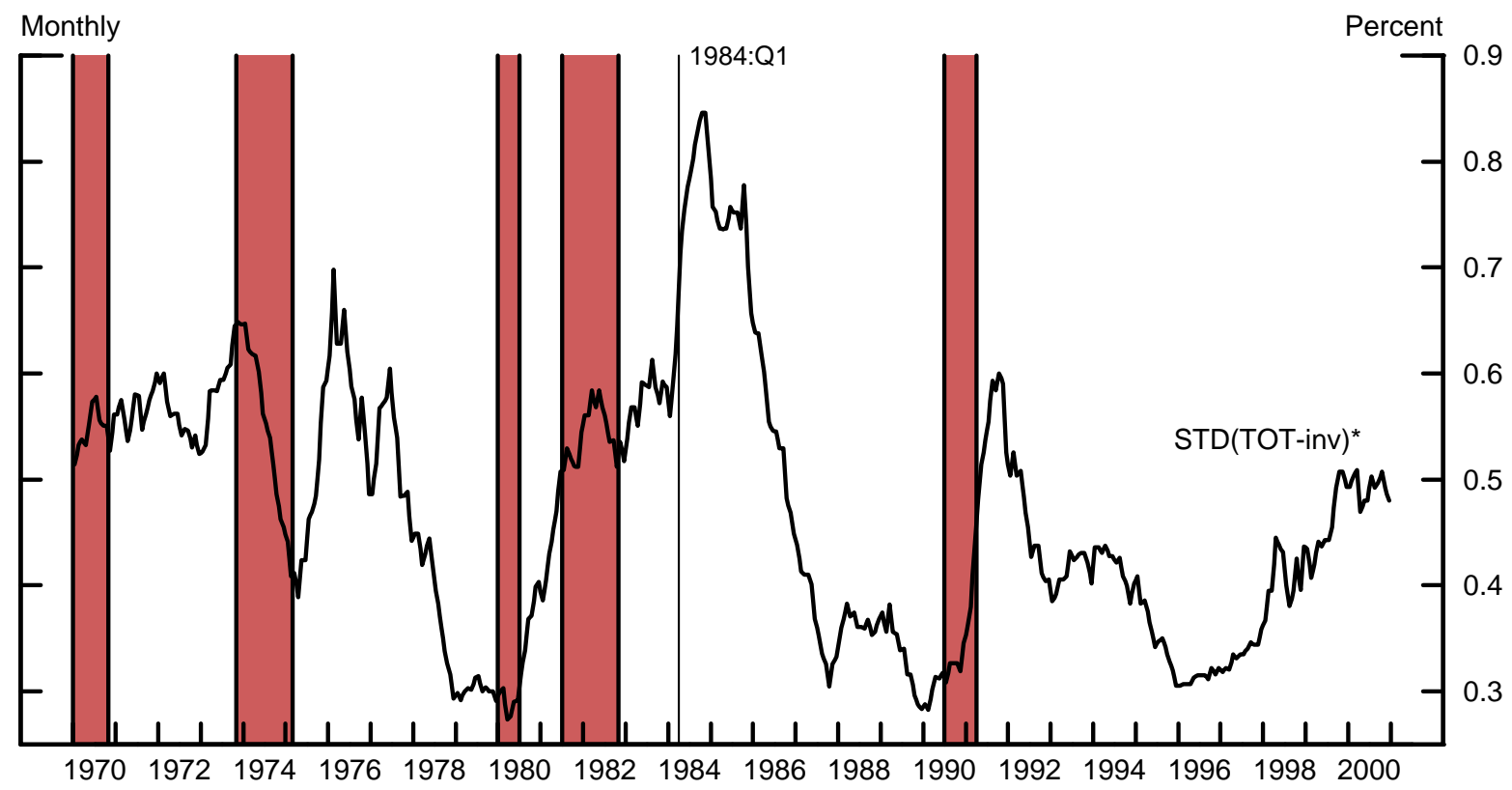

Note: The vertical line at 1984:Q1 marks the estimated date of volatility reduction for durable goods GDP.

\section{Growth Contributions of Inventories By Stage of Production}

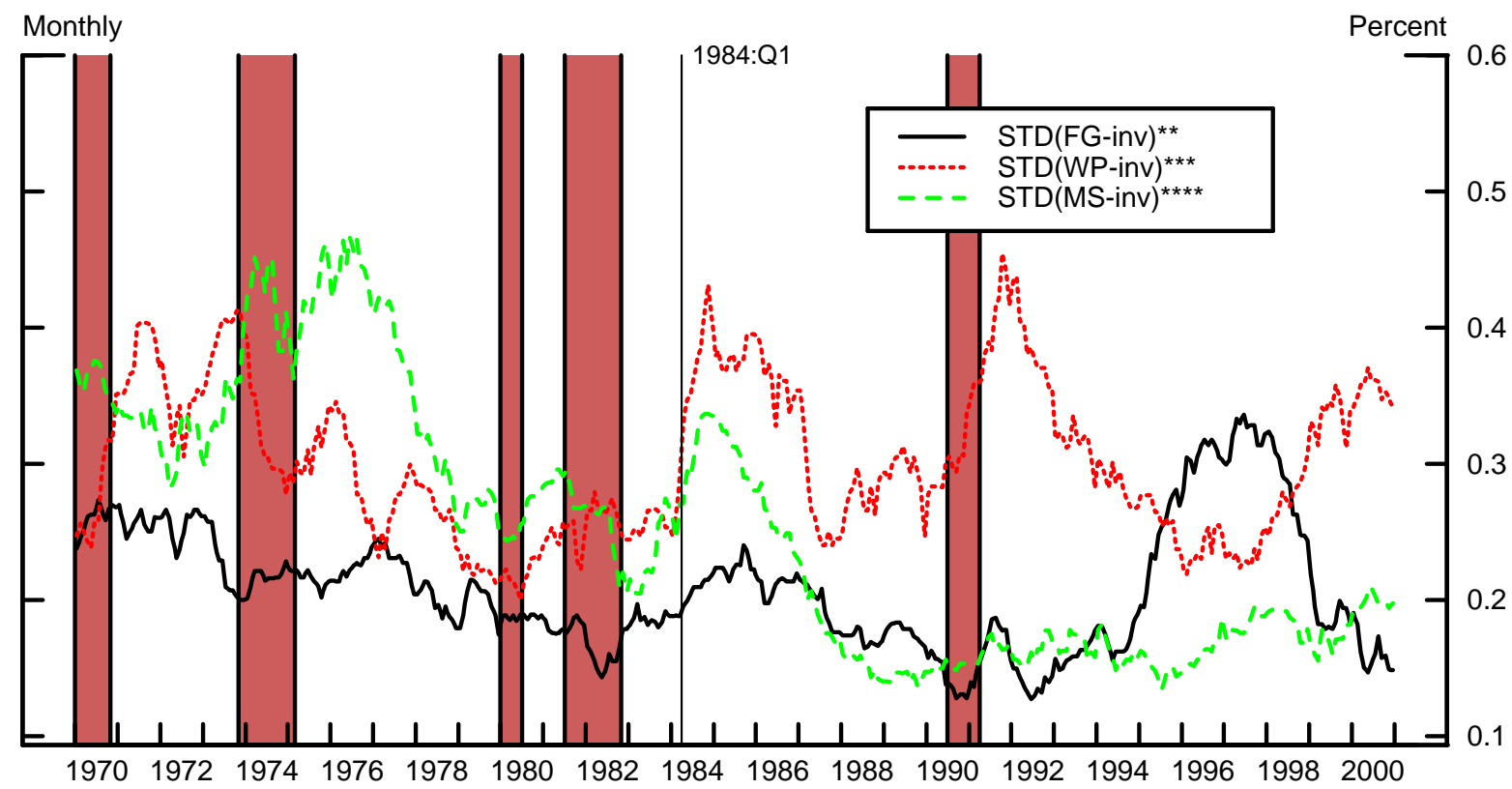

Note: The vertical line at 1984:Q1 marks the estimated date of volatility reduction for durable goods GDP.

* TOT-inv denotes the growth rate of total inventories.

** FG-inv denotes the growth contribution of finished goods inventories.

$* * *$ WP-inv denotes the growth contribution of work-in-progress inventories.

${ }^{* * * *}$ MS-inv denotes the growth contribution of materials and supplies inventories.

STD() denotes a rolling robust estimate of the standard deviation. 
Figure $3 b$

\section{Inventory Volatility in Manufacturing Nondurable Goods Sector}

Total Inventories

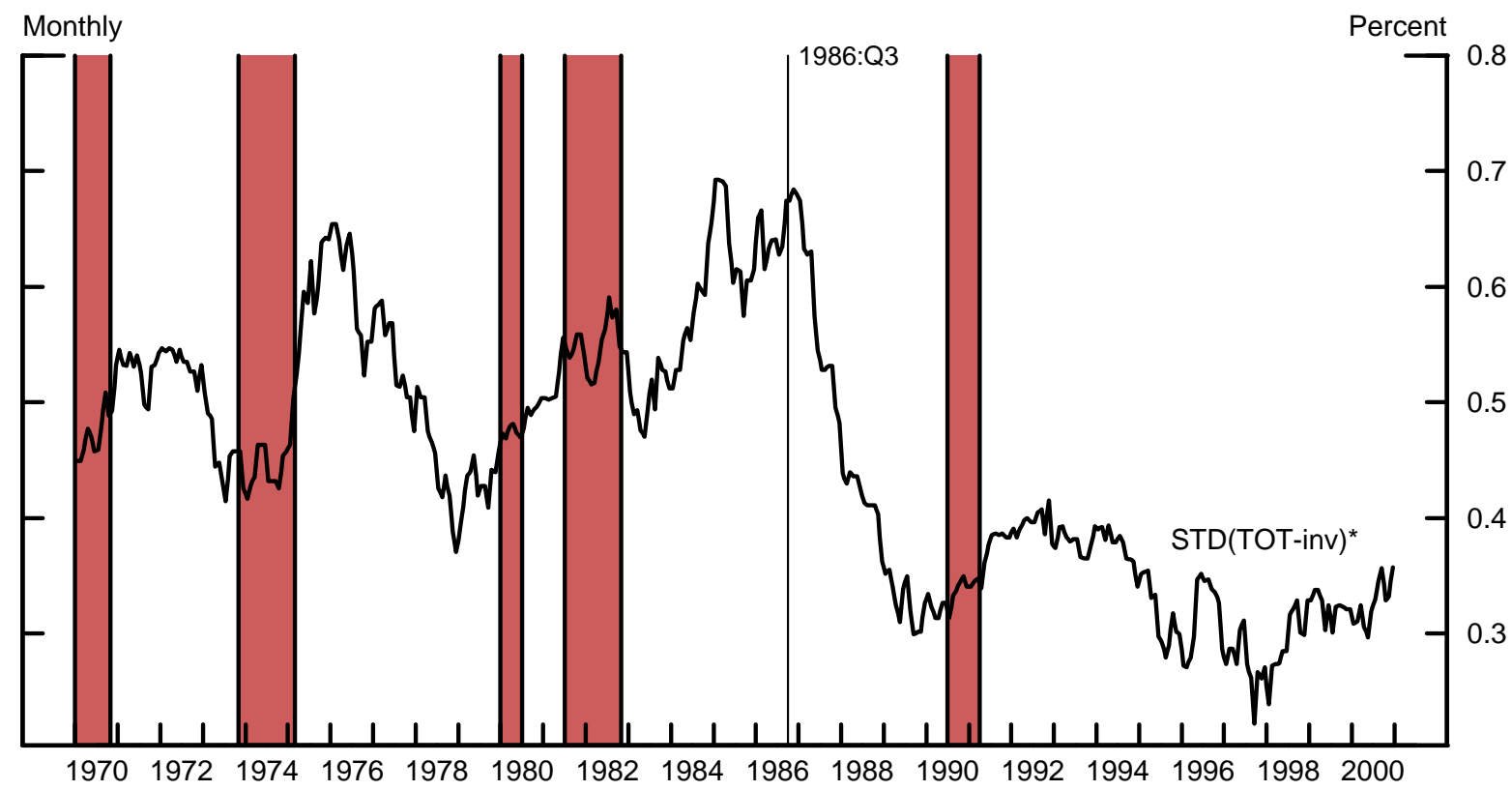

Note: The vertical line at 1986:Q3 marks the estimated date of volatility reduction for nondurable goods GDP.

\section{Growth Contributions of Inventories By Stage of Production}

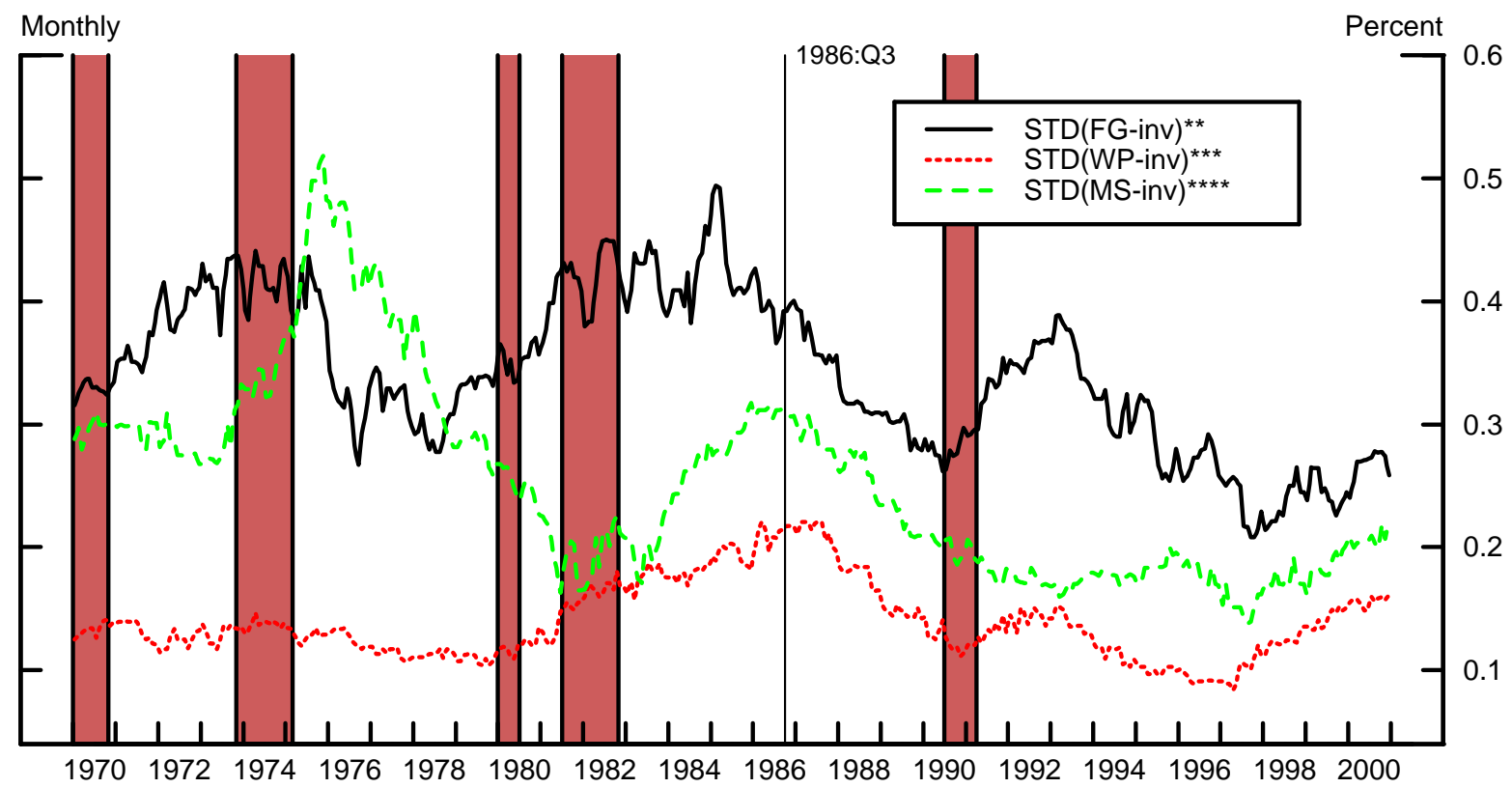

Note: The vertical line at 1986:Q3 marks the estimated date of volatility reduction for nondurable goods GDP.

* TOT-inv denotes the growth rate of total inventories.

${ }^{* *}$ FG-inv denotes the growth contribution of finished goods inventories.

*** WP-inv denotes the growth contribution of work-in-progress inventories.

**** MS-inv denotes the growth contribution of materials and supplies inventories.

STD() denotes a rolling robust estimate of the standard deviation. 
Figure 4

\section{Inventory Composition by Stage of Production}

\section{Manufacturing Durable Goods Sector}

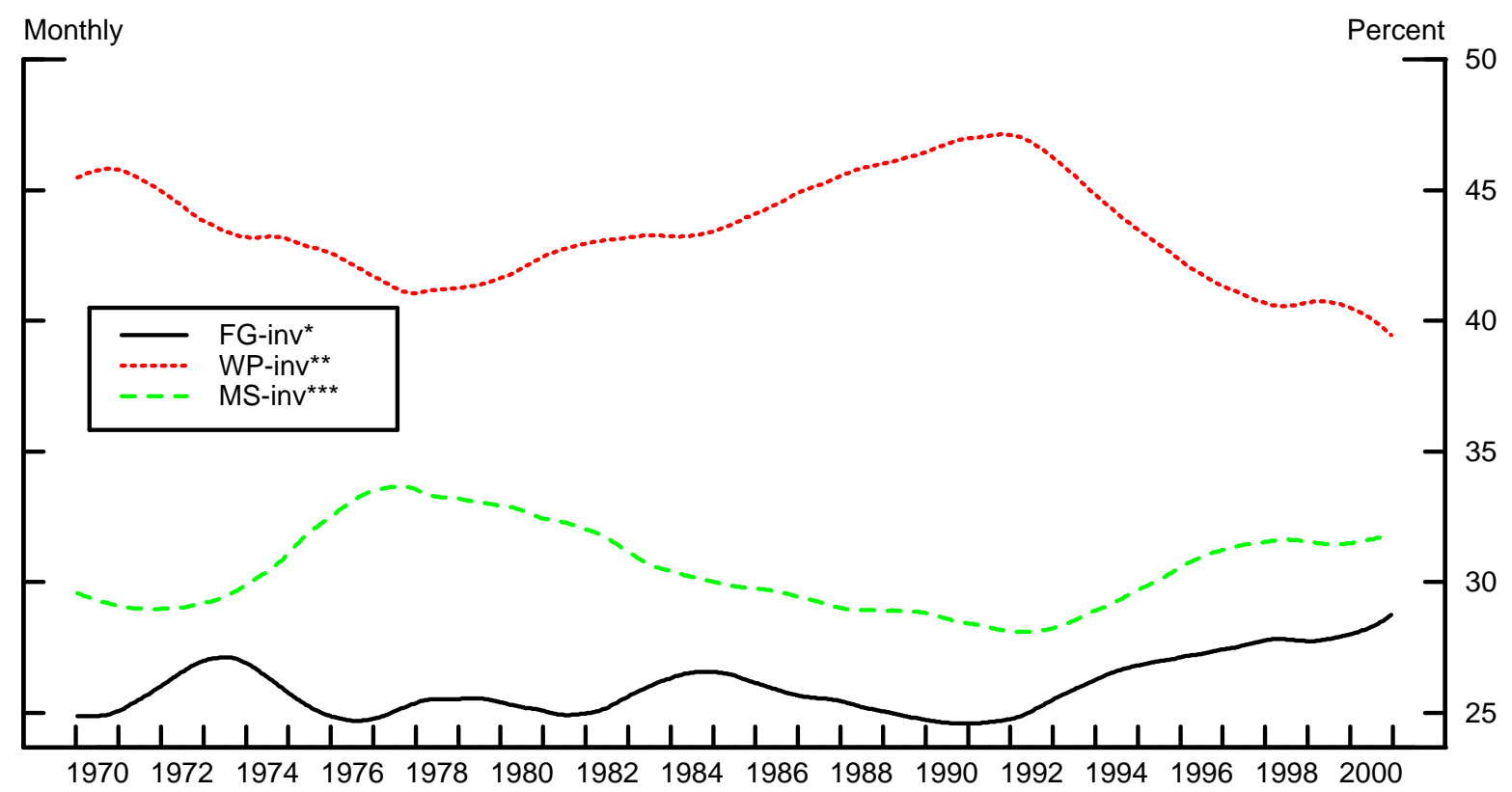

Manufacturing Nondurable Goods Sector

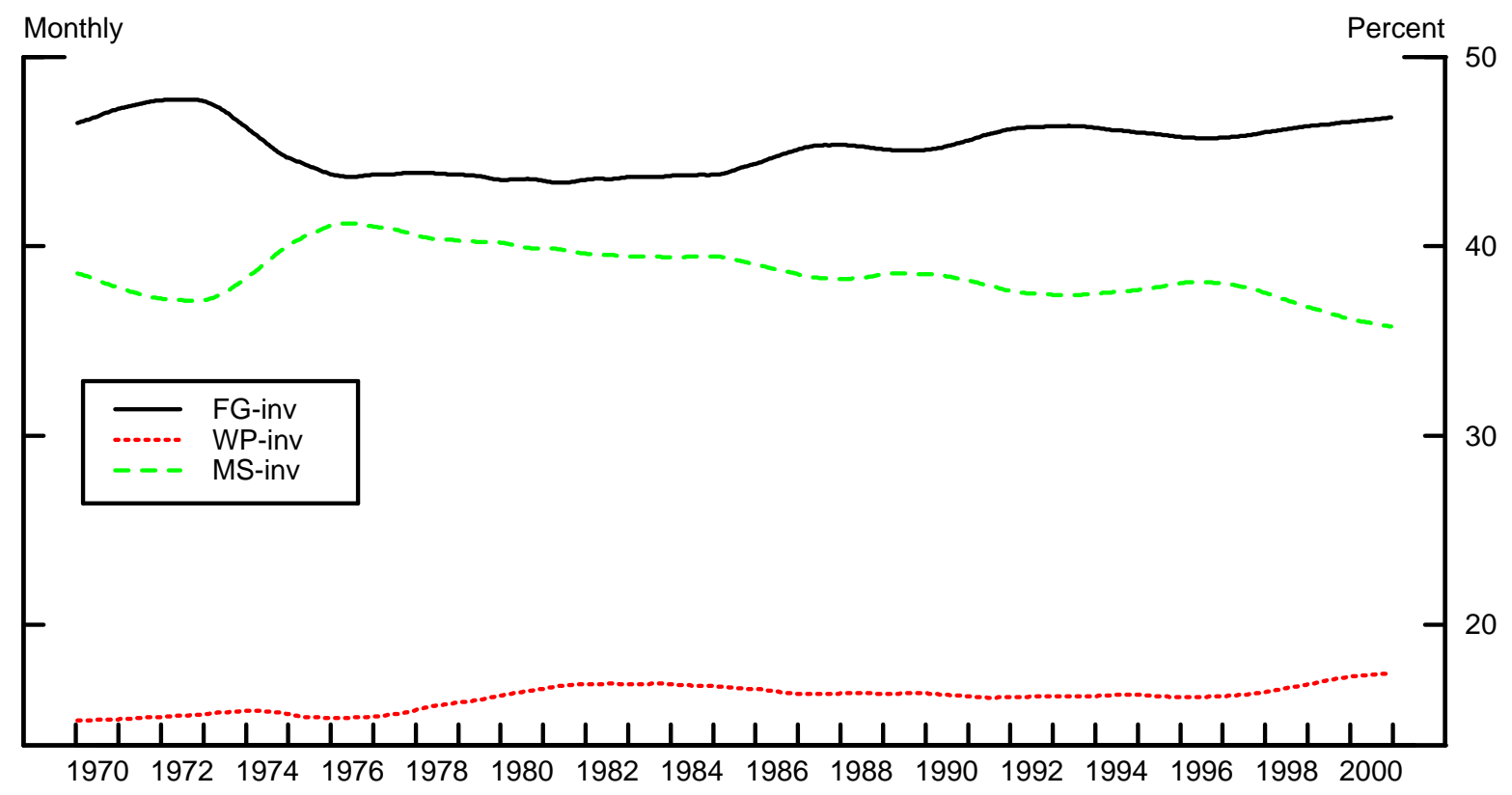

* FG-inv denotes a rolling average (nominal) share of finished goods inventories.

** WP-inv denotes the a rolling average (nominal) share of work-in-progress inventories.

*** MS-inv denotes a rolling average (nominal) share of materials and supplies inventories. 
Figure 5

\title{
Inventory Investment Correlations by Stage of Production
}

\author{
Manufacturing Durable Goods Sector
}

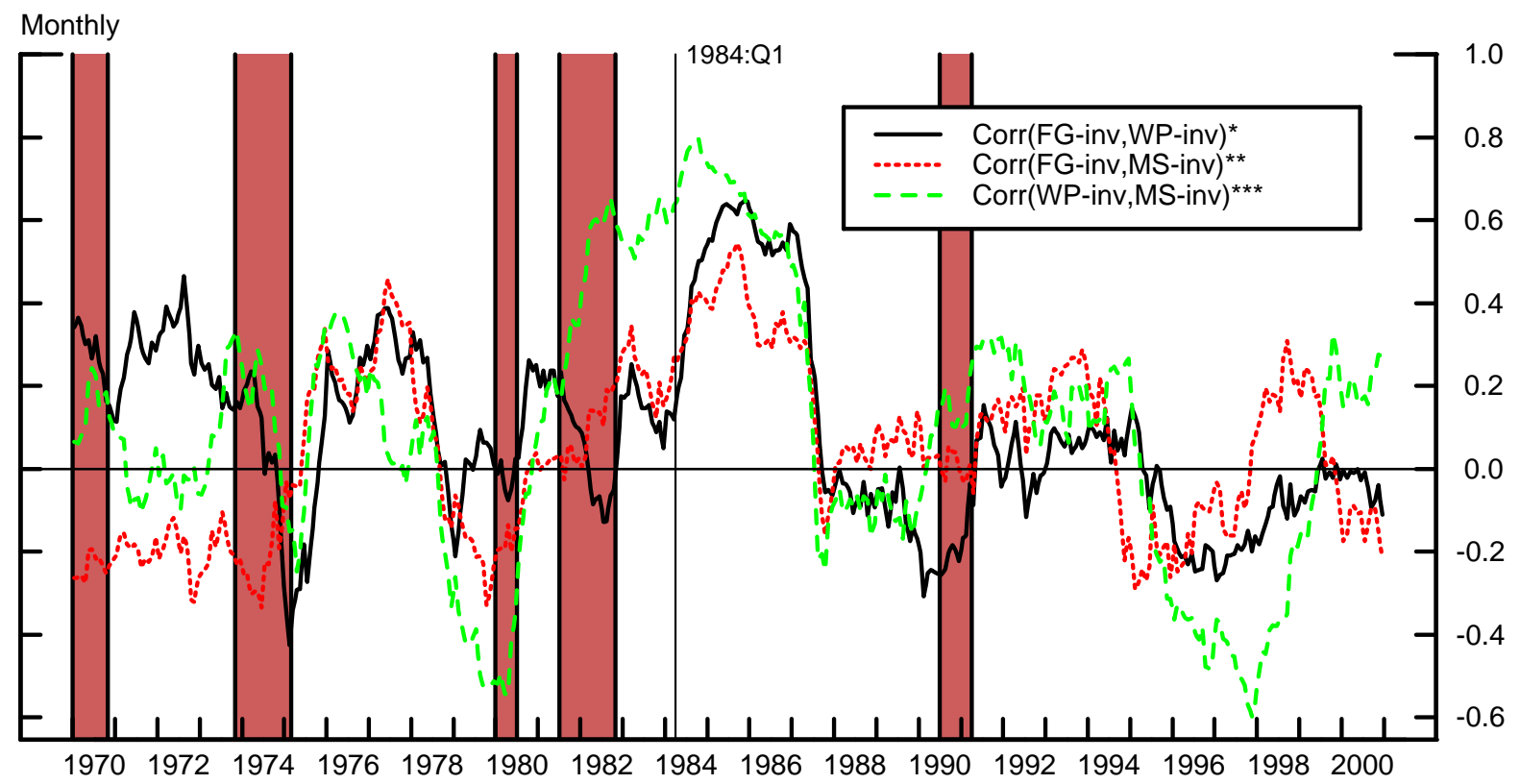

Note: The vertical line at 1984:Q1 marks the estimated date of volatility reduction for durable goods GDP.

\section{Manufacturing Nondurable Goods Sector}

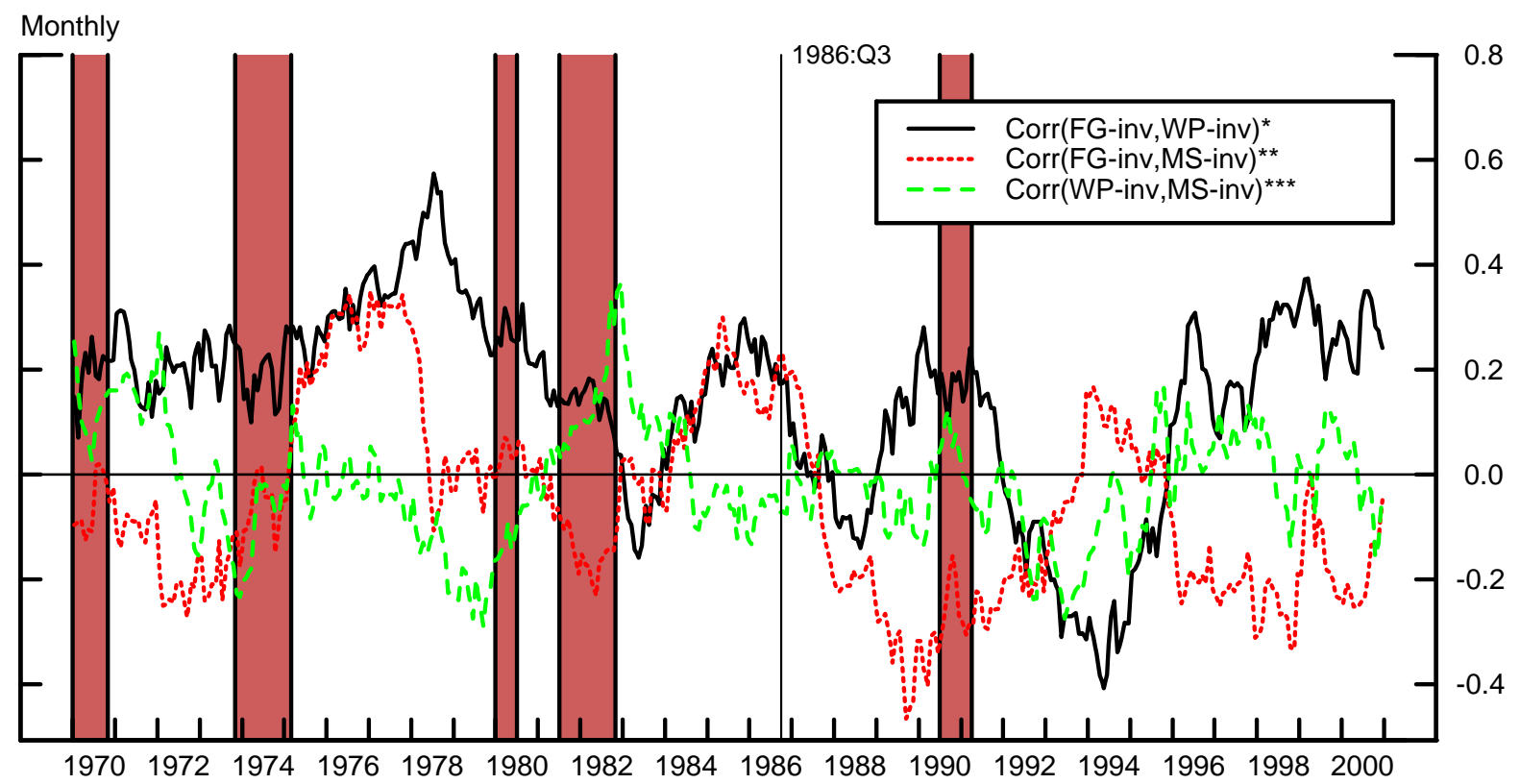

Note: The vertical line at 1986:Q3 marks the estimated date of volatility reduction for nondurable goods GDP.

* FG-inv denotes the growth contribution of finished goods inventories.

** WP-inv denotes the growth contribution of work-in-progress inventories.

*** MS-inv denotes the growth contribution of materials and supplies inventories.

Corr() denotes a rolling 5-percent trimmed correlation. 
Figure 6a

Impulse Responses to a $\mathbf{5 0}$ bps. Federal Funds Rate Shock Aggregate Block

Private Employment

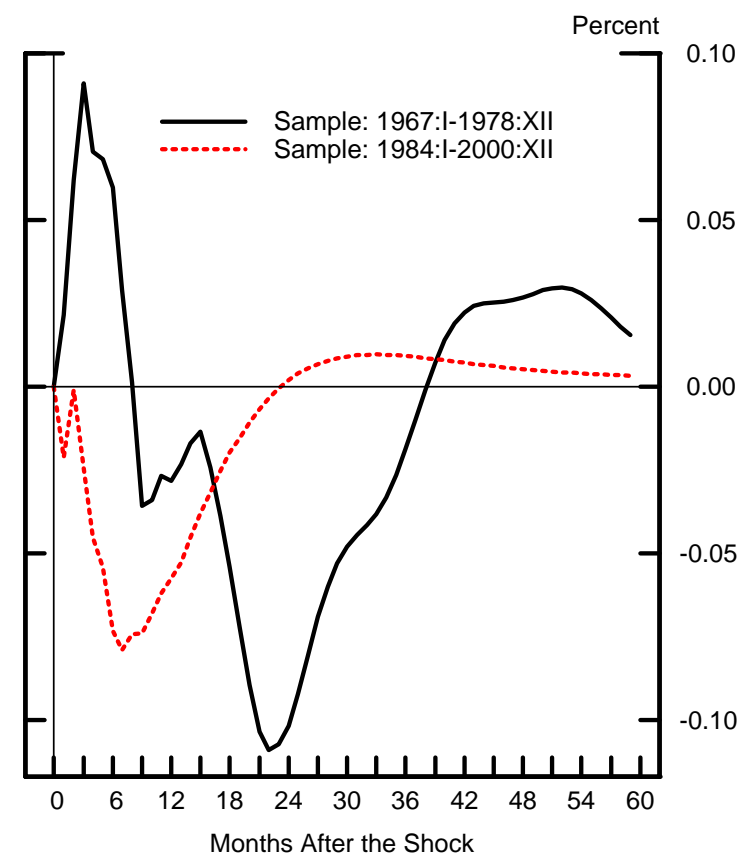

Commodity Prices

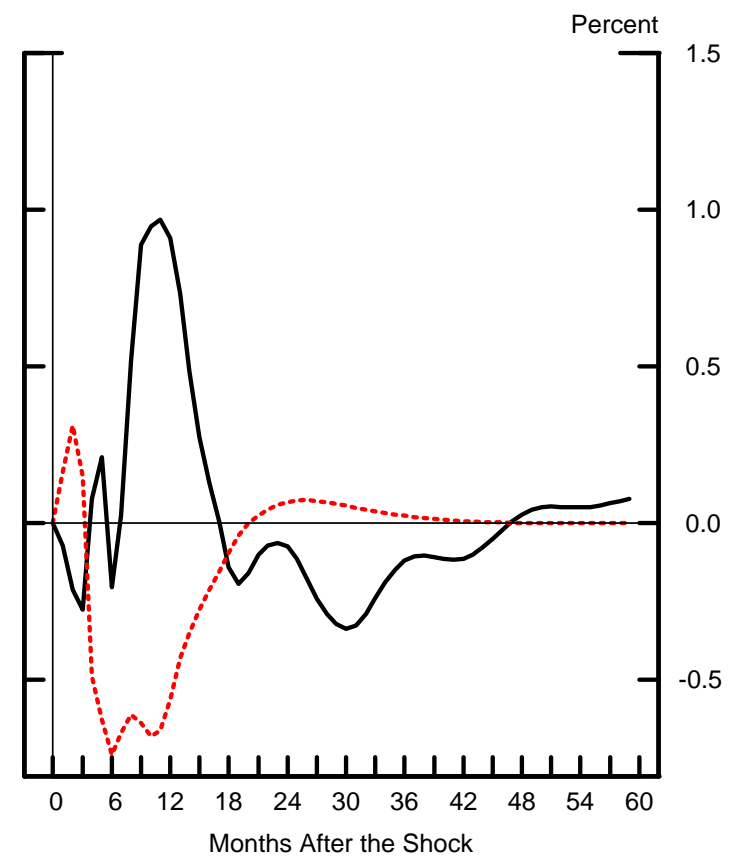

Price Level (PCE)

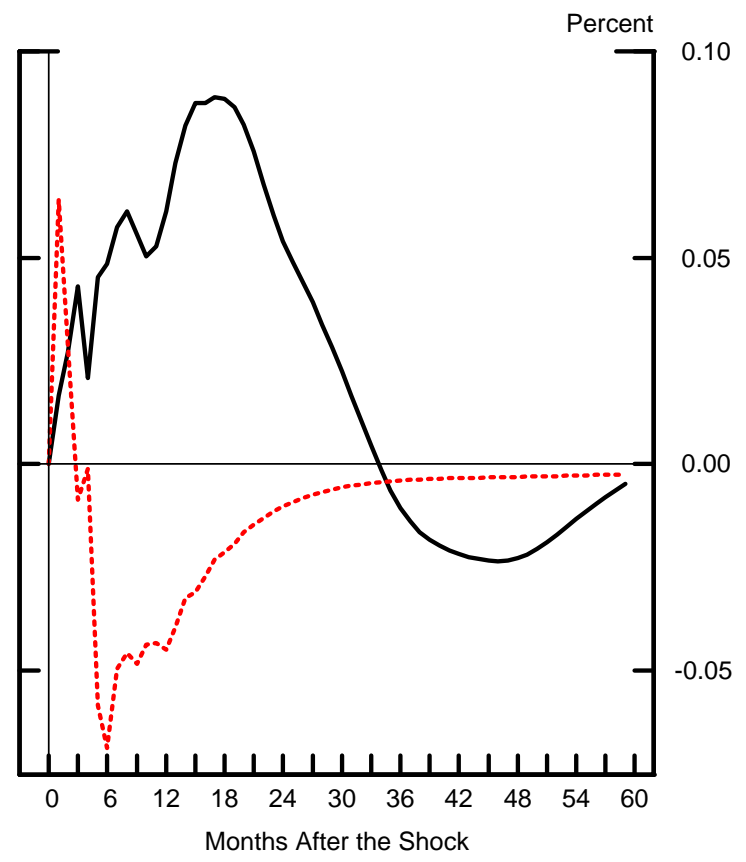

Federal Funds Rate

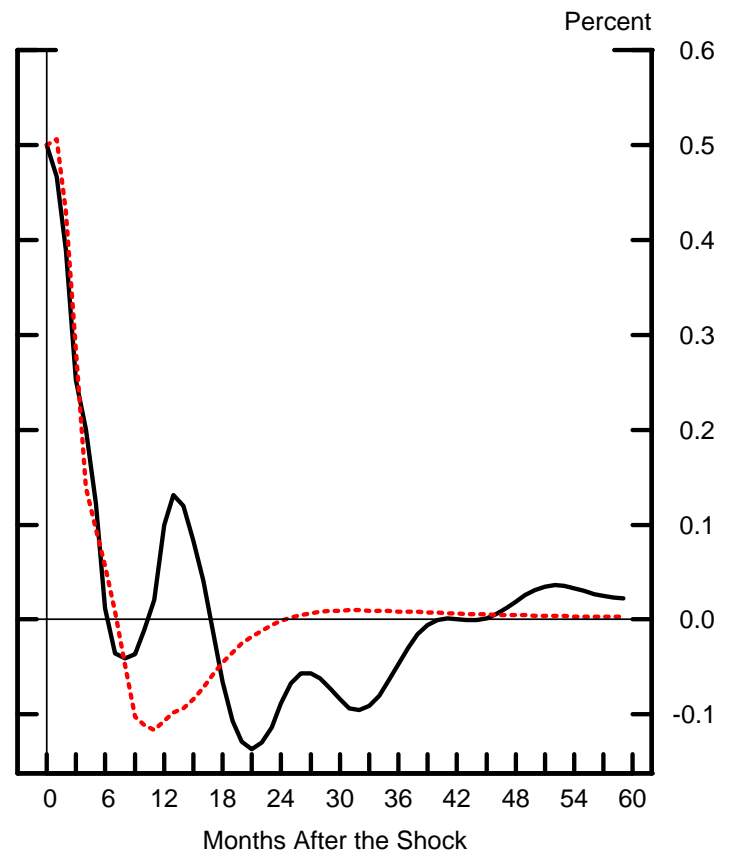




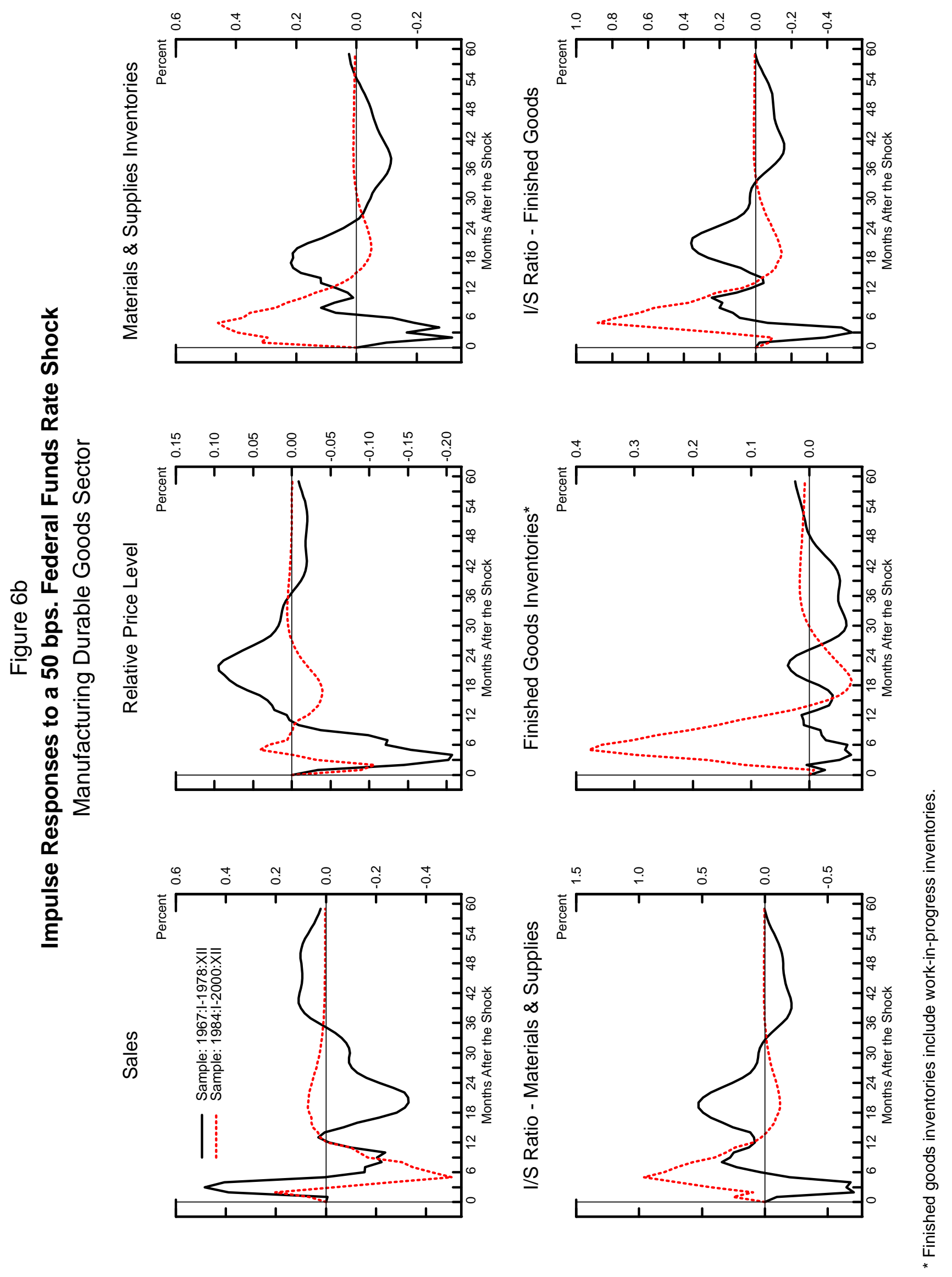




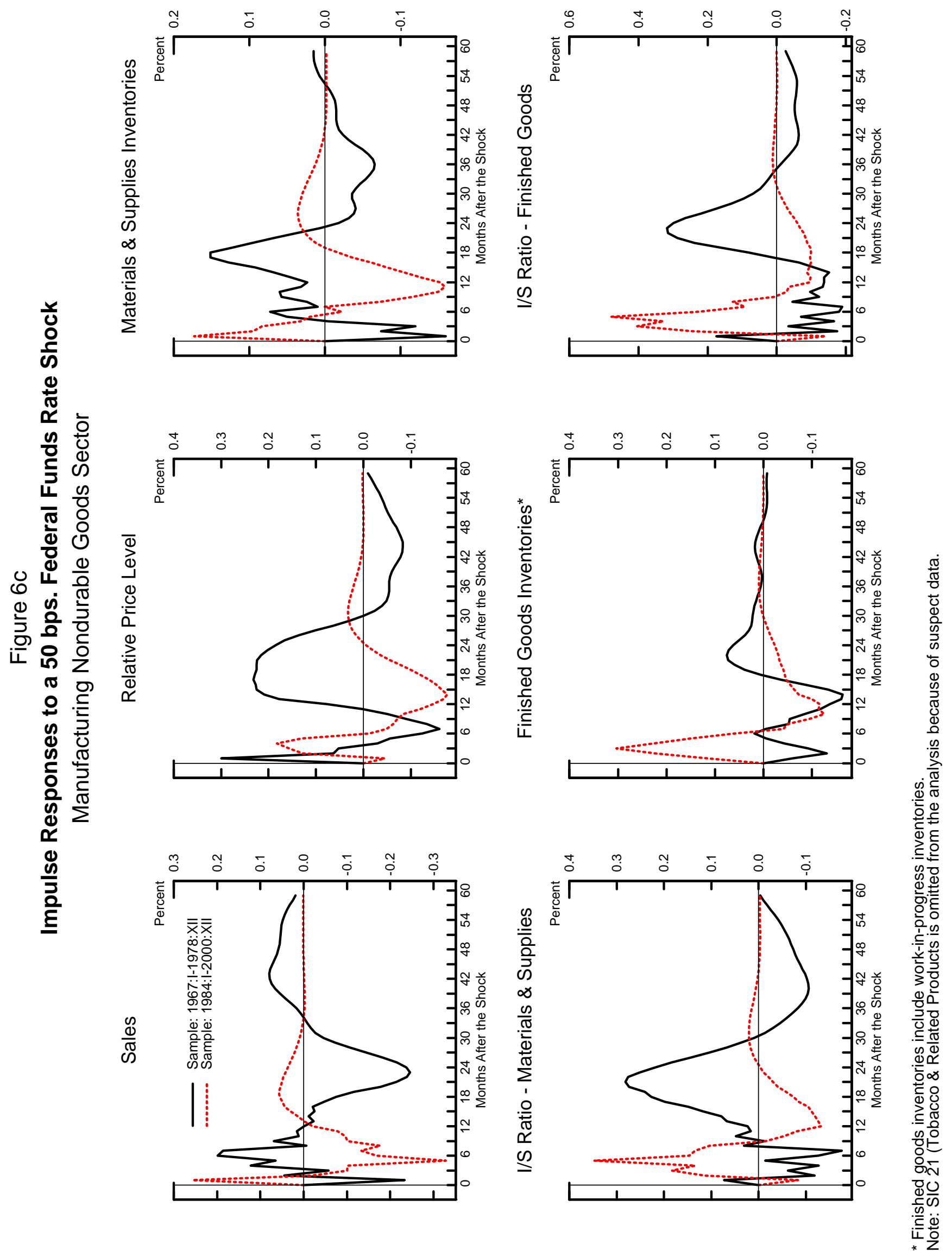


Figure $7 \mathrm{a}$

Impulse Responses to a 1\% Commodity Price Shock

Aggregate Block

Private Employment

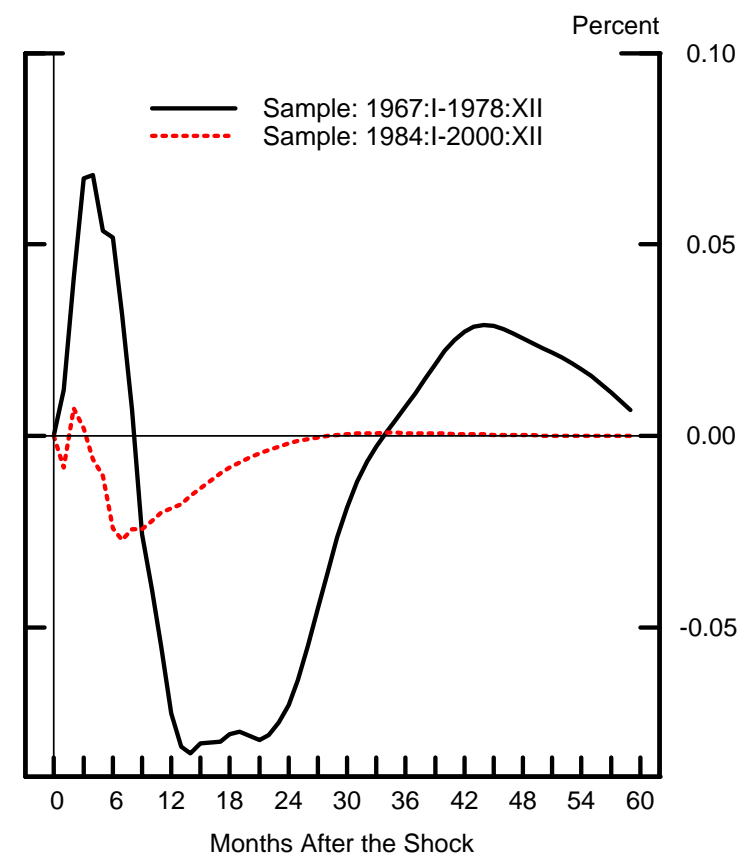

Commodity Prices

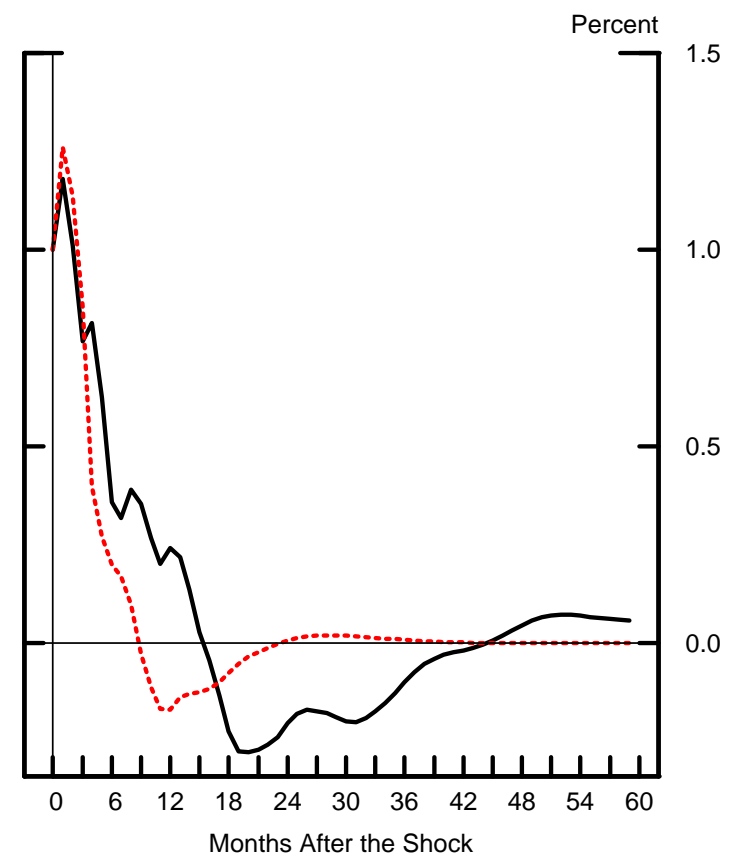

Price Level (PCE)

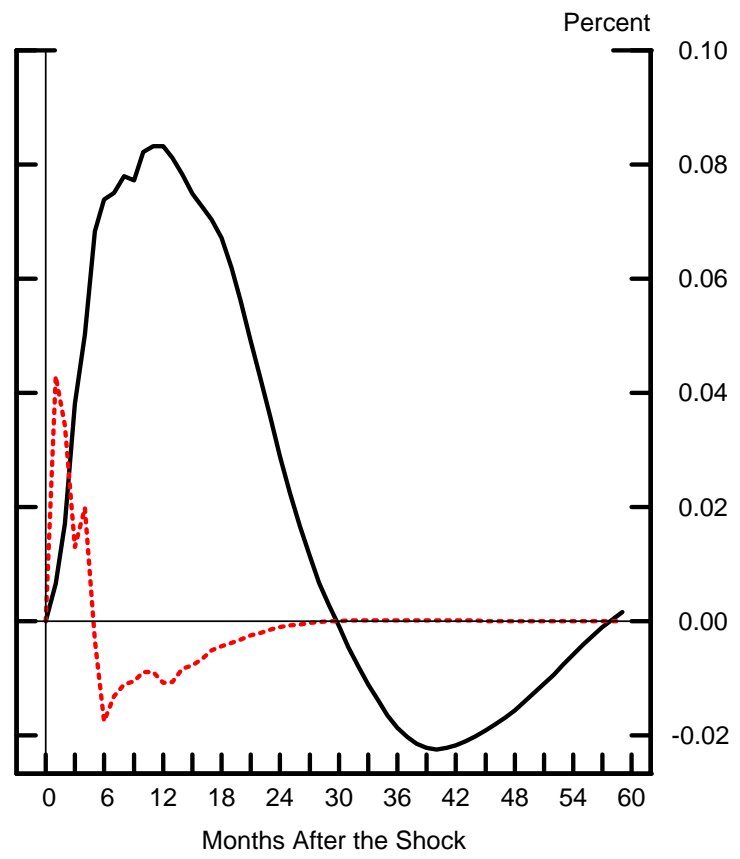

Federal Funds Rate

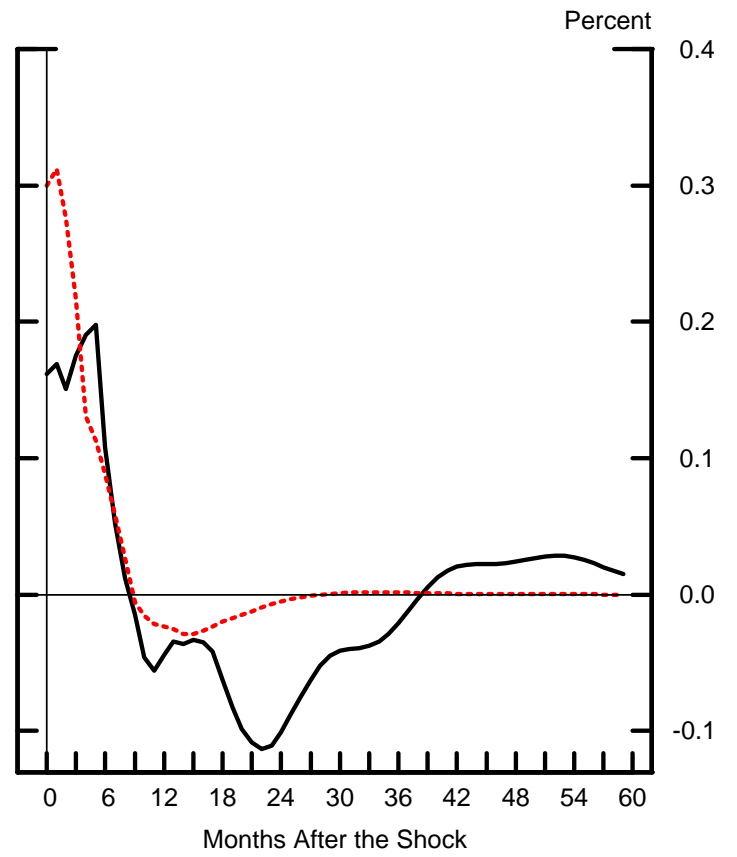




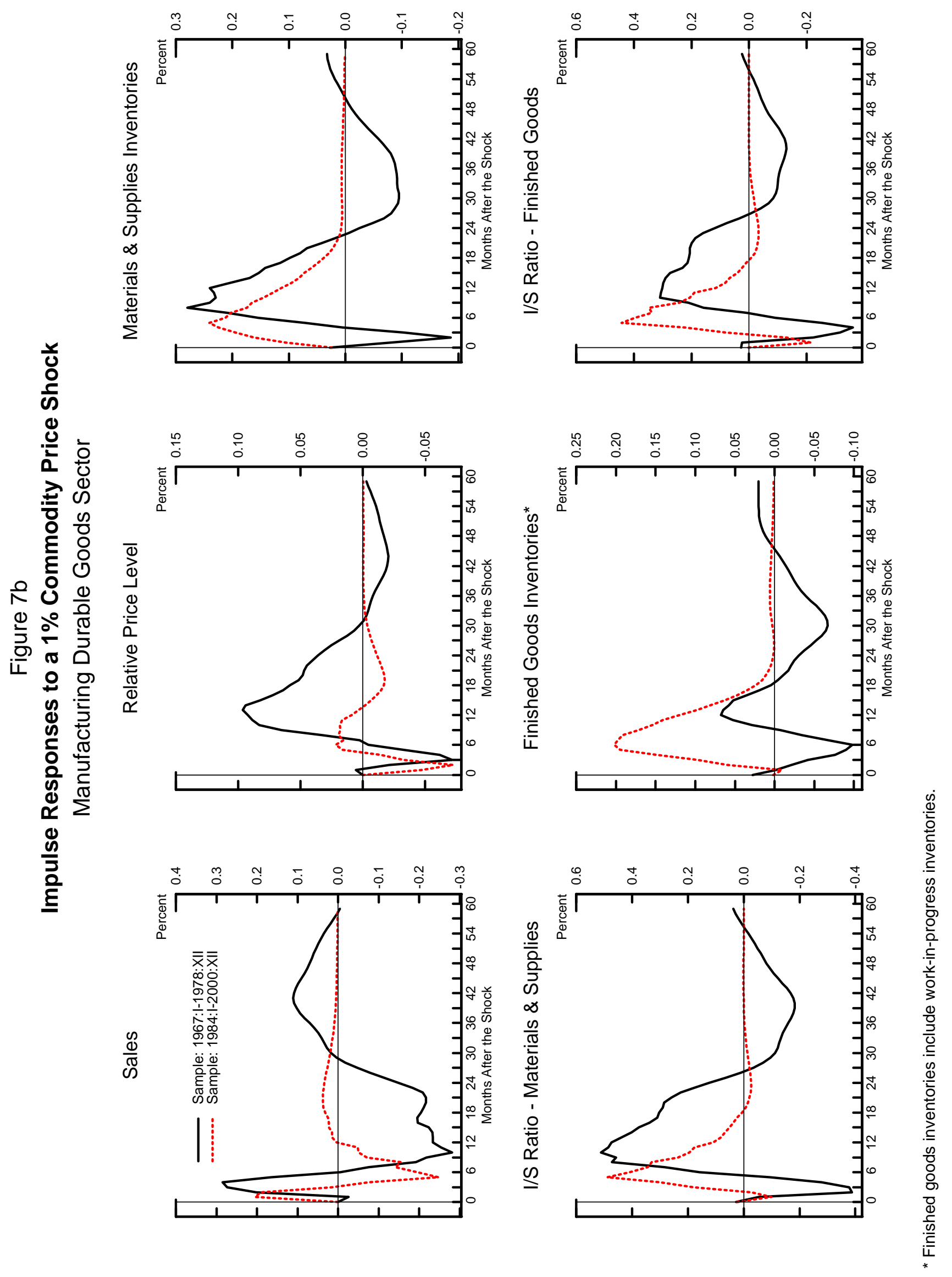




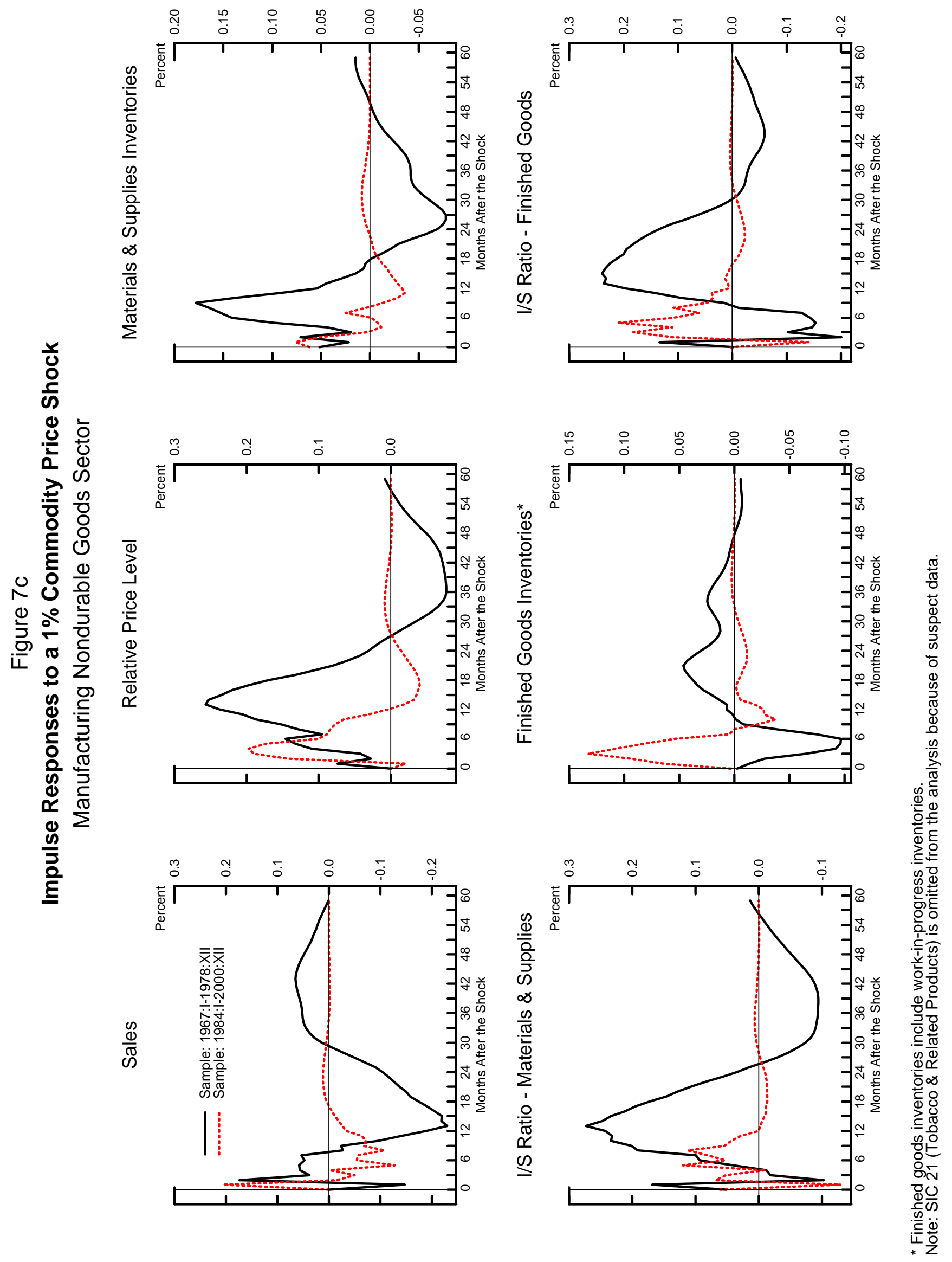

